\title{
Shrinking Goods and Sticky Prices: Theory and Evidence
}

\author{
Avichai Snir* \\ Bar-Ilan University and Humboldt-Universität zu Berlin \\ snirav@mail.biu.ac.il \\ Daniel Levy \\ Bar-Ilan University, Emory University, and RCEA \\ levyda@mail.biu.ac.il
}

\begin{abstract}
$\underline{\text { Abstract }}$
Swan's (1970) theorem predicts that consumers should be indifferent between equivalent changes in goods' prices and quantities. Empirical evidence, however, suggests that consumers often respond differently to price increases and equivalent quantity decreases. We offer a possible explanation for this puzzle by constructing and empirically testing a model in which consumers face cognitive costs when processing goods' price and quantity information. The model is based on evidence from cognitive psychology literature, and explains consumers' decision whether or not to process goods' price and quantity information. We find that consumers are more likely to process goods' price and quantity information when markets are competitive. They are more likely to process goods' price information than goods' quantity information. During holiday periods, however, they are more likely to process goods' quantity information in comparison to other periods. Our findings explain why producers sometimes adjust goods' prices and sometimes goods' quantities. In addition, they predict variability in price adjustment costs over time and across economic conditions.
\end{abstract}

Last Revision: December 16, 2010

JEL Codes: E31, L16

Key Words: Sticky Prices, Rigid Prices, Cognitive Costs of Attention, Information Processing Cost, Price Adjustment, Quantity Adjustment

For presentation at the 2011 American Economic Association Meeting, Denver, CO, USA. Session: Price Dynamics and Price Rigidity (E3), January 7, 8:00am, Sheraton, Savoy Discussant: Edward S. Knotek II, Federal Reserve Bank of Kansas City

\footnotetext{
* We thank the seminar participants at Bank of Israel, Bar-Ilan University, Humboldt University, the June 2010 Israeli Economic Association meeting, and the June 2010 Rimini Conference in Economics and Finance for comments and suggestions. We are particularly grateful to Ami Barnea, Allan Chen, Arthur Fishman, Arye Hillman, Jurek Konieczny, Michel Strawczynski, and Nissan Zussman. We gratefully acknowledge the financial support of Adar Foundation at the Department of Economics, at Bar-Ilan University. The usual disclaimer applies.

* Corresponding author: Avichai Snir, snirav@mail.biu.ac.il.
} 


\section{Introduction}

Swan's (1970) theorem predicts that consumers should be indifferent between price and quantity changes as long as the unit prices are the same. ${ }^{1}$ However, empirical evidence suggests that consumers often respond differently to equivalent price and quantity changes. For example, Gourville and Kohler (2004) find that consumers are more likely to respond to price increases than to quantity decreases. At the same time, consumers' response to quantity changes is often larger than their response to price changes, and it seems that their responses are often driven by emotions. ${ }^{2}$ Quantity and price adjustments, therefore, might have different long run effects on demand (Blinder et al., 1998, Rotemberg, 2005).

Producers seem to respond to this asymmetry in consumers’ behavior. In periods of high inflation, for example, quantity adjustments seem to be more frequent in markets where producers face strong competition than in other markets. ${ }^{3}$

Below, we construct, calibrate, and test a model which offers a possible explanation for the consumers’ puzzling behavior. In the model, consumers face cognitive costs of information processing and therefore, they must decide whether to process goods’ price information, quantity information, both or neither (Navon and Gopher, 1979, Smith et al., 2003). ${ }^{4}$ The model predicts that consumers' decisions depend on goods' attributes, on consumers' utility function, on the market structure and on economic conditions.

We test the model's predictions using data from two surveys we have conducted. In these surveys, we collected data on the information consumers have about goods' prices and quantities. We find that consumers are more likely to recall goods' quantity during holidays than during other times. We also find evidence that consumers’

\footnotetext{
${ }^{1}$ We use the term quantity to refer to goods' quantity per package. For example, the quantity of a CocaCola bottle is 0.5 litters in Europe and $20 \mathrm{fl}$ oz in the US.

${ }^{2}$ For example, one consumer who learned that an ice cream producer decreased the size of its products responded by: "Thanks goodness. This will give me a reason to stop buying ice cream”. See: www.mouseprint.org/2008/05/12/ice-cream-scoop-major-brands-downsize-again/. See also www.usatoday.com/money/industries/food/2008-06-11-shrinking-sizes N.htm. Some consumer advocates maintain an updated list of shrinking products. See, for example, incredibleshrinkinggroceries.com/.

${ }^{3}$ For example, Hershey changed the quantity of their bars 15 times during the inflationary period of the 1970s and 1980s while changing the prices only 4 times (Knotek, 2011). See also: www.foodnavigator-usa.com/Financial-Industry/Consumers-don-t-want-to-downsize-to-save-cash. ${ }^{4}$ The notion of inattentive behavior that we study here is related to a similar notion studied, for example, in Mankiw and Reis (2002, 2007, 2010), Ball, et al. (2005), Reis (2006a, 2006b, 2009), Klenow and Willis (2007), and Knotek (2010), to rationally inattentive behavior as in Sims (2003), to absent minded behavior as in Ameriks, et al. (2004), and to the notion of imperfect memory used by some game theorists. Our implementation of the notion, however, differs from the above.
} 
characteristics and goods' attributes often affect the likelihood of recalling goods' prices and quantities. For example, consumers with large families seem to be more likely to recall goods' prices and quantities. Ceteris paribus, consumers are also more likely to recall goods' prices if price variance in the category is large and if the goods' are sold in multi-unit packs such as 6-packs.

Thus, the model and the estimation results suggest that consumers' knowledge of price and quantity adjustments might vary across goods and over the cycle. Producers, therefore, will choose which feature of the product to adjust according to the consumers' attention mode: price attentive, quantity attentive, etc (Carlton, 1989). For example, producers facing price sensitive consumers are more likely to adjust quantities than prices. However, in periods when consumers have high utility from consumption, such as in holidays, producers will be more likely to increase quantities rather than cut prices. ${ }^{5}$

The paper is organized as follows. In section 2, we discuss cognitive costs of information processing and their implications for attention. In section 3 , we construct the model. In section 4, we calibrate the model and conduct comparative static experiments. In section 5, we describe the data. In section 6 we test the model's predictions and report the estimation results. Section 7 concludes.

\section{Information Processing Costs}

Findings by cognitive psychologists suggest that performing cognitive tasks requires attention, which is a resource that the brain has in limited capacity (Navon and Gopher, 1979, Kahneman and Treisman, 1984). The amount of attention assigned to a task depends on the type and priority of the task. High priority tasks and tasks that require more effort usually receive more attention than routine or automatic tasks.

Processing goods' price and quantity information costs time and effort, because it requires a performance of many subtasks, and each of these subtasks requires attention. For example, to process a good's price information, consumers have to locate the relevant price-tag, code it in visual memory, process it in working memory and finally, store it in long-term memory. While these subtasks are performed, other tasks and subtasks that require attention are cued. These steps are repeated for every piece of information processed, and, consequently, processing time and effort likely increases linearly (or

\footnotetext{
${ }^{5}$ Marginal utility of consumption might be higher during holidays for two main reasons. First, during holidays consumers often have more leisure. Second, during holidays, some of the consumption takes place in social settings. Consumption, in holidays, therefore, might have extra value as a signal of wealth (Bagwell and Bernheim, 1996, Dotsey, et al., 1999, Chevalier et al., 2003, Levy et al., 2010; Reis, 2009).
} 
almost linearly) with the number of information pieces processed. Thus, to minimize costs, consumers might choose not to process some goods' price and quantity information (Thaler 2000, Levy, et al. 2011). Following these insights, we construct a model in which consumers face cognitive costs and assess the cost and the benefits to decide which stimuli to process. In our model, processing goods’ price and quantity information is costly and consumers choose whether to process goods' price information (and thus be price-attentive), quantity information (quantity attentive), both (price and quantity attentive, or neither (inattentive).

\section{The Model}

\section{(i) Consumers}

All consumers are identical and there is a continuum of goods indexed by $i \in(0,1)$. Goods are sold in packages, and each consumer purchases $C(i)$ packages of good $i \in(0,1)$. Each package of good $i$ contains $Q(i)$ units of good $i$, which we denote as the quantity (i.e., the package size) of good $i$. Consumers therefore consume $C(i) Q(i)$ units of good $i$.

Each consumer is endowed with one unit of time which he uses for labor, leisure and processing goods' information. We denote the time that consumers dedicate to processing goods' information by $\mathrm{T} \in[0,1]$. We denote the time they dedicate to labor by $N \in[0,1-\mathrm{T}]$. We denote the time they dedicate to leisure by $L \in[0,1-\mathrm{T}-N]$. We denote their nominal wage by $W$. Thus, their nominal income, $Y$, is given by $Y=N W$.

Following Galí (2008, p. 41) and Blanchard and Fischer (1989, p. 376), we assume that goods are imperfect substitutes, and that the utility function is:

$U(C, N, \mathrm{~T})=\frac{C^{1-\sigma}}{1-\sigma}-\frac{N^{1+\varphi}}{1+\varphi}-\frac{\mathrm{T}^{1+\varphi}}{1+\varphi}, \quad \sigma \in(0,1), \quad \varphi \geq 0$

where $C$ is a Dixit-Stiglitz consumption aggregator defined by

$$
C=\left\{\int_{0}^{1}[C(i) Q(i)]^{\frac{\varepsilon-1}{\varepsilon}} d i\right\}^{\frac{\varepsilon}{\varepsilon-1}}
$$

In this specification, $-\sigma$ is the elasticity of marginal utility with respect to consumption, $\varphi \geq 0$ is the elasticity of marginal disutility with respect to labor and with 
respect to the time devoted to processing goods' information, and $\varepsilon>1$ is the elasticity of substitution between goods.

\section{(ii) Producers}

Because we focus on consumers' behavior, we follow Reis (2006a) and Falkinger (2008) in assuming that producers' price setting decisions are driven by exogenous shocks to their marginal costs.

We assume that there is a continuum of monopolistically competitive producers $i \in(0,1)$. Each producer produces a single good, such that producer $i$ produces good $i$. The producers face constant marginal costs. We denote the marginal cost of producer $i$ by $\Psi(i)$, with $E\{\Psi(i)\}=\Psi$.

Given the consumers' utility function (1) and the elasticity of substitution between goods $\varepsilon$, the producers set their prices to equal the marginal costs times the desired markup (Galí, 2008, p. 44). Denoting the price of good $i$ by $P(i)$, the desired markup, $\frac{\varepsilon}{\varepsilon-1}$ by $\mu$, and the expected price by $P^{e} \equiv E[P(i)]$, we have:

$$
P(i)=\mu \Psi(i) \text {, and }
$$

$$
P^{e}=\mu \Psi
$$

We assume that proportion $1-\theta \in(0,1)$ of the producers produce their goods at marginal costs that equal the expected cost, $\Psi$.

The rest, proportion $\theta \in(0,1)$ of the producers, experience marginal cost shocks $\eta(i)$. Their marginal costs are therefore $\Psi(i)=\Psi+\eta(i)$. We assume that the marginal cost shocks follow a symmetric, i.i.d. distribution with mean 0 and constant variance. We also assume that $|\eta(i)|<\Psi \quad \forall i \in(0,1)$, to ensure that the marginal costs of all producers are positive.

A proportion $\theta_{P} \in(0, \theta)$ of the producers who experience cost shocks adjust their prices. The price that these producers set is given by

$$
P(i)=\mu[\Psi(i)+\eta(i)] .
$$


The rest of the producers who experience cost shocks, proportion $\theta_{Q} \equiv \theta-\theta_{P}$, respond by adjusting their quantities. ${ }^{6}$ Denoting the expected quantity as $Q^{e} \equiv E[Q(i)]$, these producers adjust their quantities to

$Q(i)=\kappa(i) Q^{e}$,

where $\kappa(i)$ is the proportion of the expected quantity that solves:

$$
\frac{P(i)}{Q^{e}}=\frac{P}{\kappa(i) Q^{e}}
$$

Equation (6) states that the unit-price of good $i, \frac{P(i)}{Q(i)}$, will be the same whether the producer adjusts the price (LHS) or the quantity (RHS) in response to a cost shock of a given size. Solving (6) for $\kappa(i)$ yields:

$$
\kappa(i)=\frac{\Psi}{\Psi+\eta(i)}
$$

Thus, producers who do not experience a marginal cost shock set the quantity equal to the expected quantity, $Q^{e}$. Producers who experience a cost shock either adjust the price according to (5) or the quantity according to (5') and (7).

\section{(iii) Consumers' Decision Making Process}

We assume that consumers purchase goods in shops, that all shops are identical and that the travel costs are zero. When in a shop, consumers have the option of processing goods’ price information, goods' quantity information, both or neither. All goods enter the utility function symmetrically, and therefore the consumers treat them symmetrically. We therefore assume that consumers either choose to process the price information of all goods, or they choose not to process the price information of any good. Similarly, we assume that consumers either choose to process the quantity information of all goods, or they choose not to process the quantity information of any good. ${ }^{7}$

Consumers therefore choose one of four attention modes. Price attentive consumers process only good's price information. They therefore know the price of every

\footnotetext{
${ }^{6}$ Although we do not model the producers' decision process, it is likely that decisions on whether to adjust prices or quantities depend on the exact nature of the shocks and the market structure. For example, some producers argue that in competitive markets, it is sometimes better to downsize a good rather then to increase its price. Source: www.usatoday.com/money/industries/food/2008-06-11-shrinking-sizes_N.htm. 7 This assumption is similar the one made by Gabaix and Laibson (2006) and Armstrong and Chen (2009) who assume that a certain proportion of the consumers have information about all goods, while the rest of the consumers do not have information about any good.
} 
good $P(i), i \in(0,1)$, but assume that all goods' quantities are equal to the expected quantity, $Q^{e}$. Quantity attentive consumers process only goods’ quantity information. Therefore, they know the quantity of every good $Q(i), i \in(0,1)$, but assume that all goods' prices are equal to the expected price, $P^{e}$.

Price and quantity attentive consumers process both the price and the quantity information of every good $i$. They therefore know the price $P(i)$, and the quantity $Q(i)$ of every good $i \in(0,1)$. Inattentive consumers do not process goods’ price nor goods’ quantity information. They, therefore, assume that every good's price and quantity equal their expected values $P^{e}$ and $Q^{e}$, respectively.

We assume that consumers choose the attention mode which maximizes their utility. Thus, they have to assess the costs and the benefits of each attention mode.

Following the discussion above, we measure the costs of processing information in terms of the amount of time dedicated to information processing. We denote the cost of processing one price information by $\tau_{P}$ and the cost of processing one quantity information by $\tau_{Q}$. To ensure that consumers can process both price and quantity per package information, we assume that $\tau_{P}+\tau_{Q} \leq 1$. The benefits of processing price and quantity information are the lower unit-prices that are paid when substituting high unit price goods with low unit price goods. ${ }^{8}$ To assess the expected benefits in each attention mode, we find the demand for each good $i \in(0,1)$ and use it to derive the price level in each attention mode. Following Galí (2008), we define the price level that consumers face $P=\frac{1}{C}\left[\int_{0}^{1} C(i) P(i) d i\right]$.

The demand of price attentive (PA) consumers for good $i, C_{P A}(i)$, and the price level they face, $P_{P A}$, are respectively, given by (see the appendix)

\footnotetext{
${ }^{8}$ For example, assume that brand A of mineral water is sold for $\$ 1$ in bottles of $20 \mathrm{fl} \mathrm{oz}$ and brand B for $\$ 0.9$ in bottles of $16 \mathrm{fl} \mathrm{oz}$. A price and quantity attentive consumer who is indifferent between the brands picks brand A and pays $5 \mathbb{\$}$ per $\mathrm{fl}$ oz. A price attentive consumer who is indifferent between the goods picks brand $\mathrm{B}$ and pays about $12.5 \%$ more (5.56\$) per fl oz.
} 


$$
\begin{aligned}
& C_{P A}(i)=\left[\frac{P(i)^{-\varepsilon}}{\int_{0}^{1} P(j)^{1-\varepsilon} d j}\right] Y_{P A} \text {, and } \\
& P_{P A}=\frac{\int_{0}^{1} P(j)^{1-\varepsilon} d j}{\left[\int_{0}^{1} P(j)^{1-\varepsilon} Q(j)^{\frac{\varepsilon-1}{\varepsilon}} d j\right]^{\frac{\varepsilon}{\varepsilon-1}}} .
\end{aligned}
$$

The demand of quantity attentive (QA) consumers for good $i, C_{Q A}(i)$, and the price level they face, $P_{Q A}$, are given respectively by (see the appendix)

$$
\begin{aligned}
& C_{Q A}(i)=\left[\frac{Q(i)^{\varepsilon-1}}{\int_{0}^{1} Q(j)^{\varepsilon-1} d j}\right] \frac{Y_{Q A}}{P(i)}, \text { and } \\
& P_{Q A}=\frac{\int_{0}^{1} P(j) Q(j)^{\varepsilon-1} d j}{\left[\int_{0}^{1} Q(j)^{\varepsilon-1} d j\right]^{\frac{\varepsilon-1}{\varepsilon}} .}
\end{aligned}
$$

The demand of price and quantity attentive (PQA) consumers for good $i$, $C_{P Q A}(i)$, and the price level they face, $P_{P Q A}$, are given respectively by (see the appendix)

$$
\begin{gathered}
C_{P Q A}(i)=\frac{\left[\frac{P(i)}{Q(i)}\right]^{1-\varepsilon} Y_{P Q A}}{P(i) \int_{0}^{1}\left[\frac{P(i)}{Q(i)}\right]^{1-\varepsilon} d j}, \text { and } \\
P_{P Q A}=\left\{\int_{0}^{1}\left[\frac{P(j)}{Q(j)}\right]^{1-\varepsilon} d j\right\}^{\frac{1}{1-\varepsilon}} .
\end{gathered}
$$

The demand of price and quantity inattentive (IA) consumers for good i, $C_{I A}(i)$, and the price level that they face, $P_{I A}$, are given respectively by (see the appendix) 
$C_{I A}(i)=\frac{Y_{I A}}{P(i)}$

$P_{I A}=\left\{\int_{0}^{1}\left[\frac{P(i)}{Q(i)}\right]^{\frac{\varepsilon}{\varepsilon-1}} d i\right\}^{\frac{\varepsilon}{1-\varepsilon}}$.

Thus, equation (14) states that inattentive consumers spend an equal fraction of their income on each good. Thus, the number of units of each good $i \in(0,1)$ they purchase equals their expenditure on that good, $Y_{I A}$, divided by the good's price $P(i)$.

Consequently, they do not substitute goods that have high unit-prices, $\frac{P(i)}{Q(i)}$, with goods that have lower unit-prices, and therefore they face a higher price level than consumers who do substitute.

Price and quantity attentive consumers, on the other hand, process both goods' price information and goods' quantity information. Therefore, equation (12) states that they base their consumption decisions on the ratio of goods' unit-prices, $\frac{P(i)}{Q(i)}$ and an aggregate of all goods' unit-prices, $\int_{0}^{1}\left[\frac{P(j)}{Q(j)}\right]^{1-\varepsilon} d j$. Consequently, they substitute high unit price goods with low unit price goods and therefore, the price level they face (13), is lower than the price level inattentive consumers face.

Price attentive consumers substitute high price goods with low price goods, but they do not substitute goods that have small quantities with goods that have large quantities. Thus, their demand for good $i$, (8), depends negatively on the ratio of goods' prices and an aggregate of all prices, $\int_{0}^{1} P(j)^{1-\varepsilon} d j$, but it does not depend on goods' quantities. Consequently, goods' quantities do not appear in the numerator of the price level they face, (9), because the numerator is determined by the number of packages they purchase. The penalty price attentive consumers pay for not processing goods' quantity information is represented by the effect that goods' quantities have on the denominator of (9). Because price attentive consumers do not process goods’ quantity information, 
goods with small quantity have a negative effect on the size of the denominator and, therefore, a positive effect on the price level that price attentive consumers face.

Quantity attentive consumers substitute goods that have small quantities with goods that have large quantities, but they do not substitute goods that have high prices with goods that have low prices. Thus, the share of income that quantity attentive consumers spend on good $i,(10)$, depends positively on the ratio of the good's quantity, $Q(i)$, and an aggregate of all goods' quantities, $\int_{0}^{1} Q(j)^{\varepsilon-1} d j$. The number of packages of good $i \in(0,1)$ they purchase, $C_{Q A}(i)$, is therefore given by their expenditure on that good divided by its price, $P(i)$. Because quantity attentive consumers do not process goods’ price information, goods' prices do not appear in the denominator of the price level they face, (11), because the denominator is determined by the number of packages they purchase. The penalty quantity attentive consumers pay for not processing goods price information is given by the positive effect that prices have on the numerator of (11). Because quantity attentive consumers do not process price information, goods with high prices have a positive effect on the price level faced by quantity attentive consumers.

Because price attentive and quantity attentive consumers make some of the substitutions that price and quantity attentive consumers make but not all, the price level they face is lower than the price level that inattentive consumers face but higher than the price level that price and quantity attentive consumers face.

Given the price level under each attention mode, consumers choose the attention mode that maximizes their utility (1), subject to their income and time constraints:

$$
\max \left[U_{k}(C, N, \mathrm{~T})\right]=\max \left\{\frac{C_{k}^{1-\sigma}}{1-\sigma}-\frac{N_{k}^{1+\varphi}}{1+\varphi}-\frac{\mathrm{T}_{k}^{1+\varphi}}{1+\varphi}\right\}
$$

s.t.

$$
\begin{aligned}
& C_{k} P_{k}=Y_{k} \\
& N_{k} \in\left[0,1-\mathrm{T}_{k}\right]
\end{aligned}
$$

where $C_{k}$ is the aggregate consumption (2) in attention mode $k, N_{k}$ is the time dedicated to labor in attention mode $k$, $\mathrm{T}_{k}=\delta_{P}(k) \tau_{P}+\delta_{Q}(k) \tau_{Q}$ 
is the time spent on processing goods' information in attention mode $k, \delta_{P}$ and $\delta_{Q}$ are indicator functions defined by

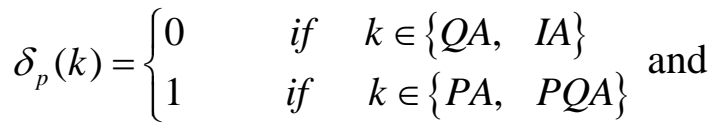

$$
\begin{aligned}
& \delta_{q}(k)=\left\{\begin{array}{llll}
0 & \text { if } & k \in\{P A, & I A\} \\
1 & \text { if } & k \in\{Q A, & P Q A\}
\end{array},\right. \text {, } \\
& Y_{k}=N_{k} W
\end{aligned}
$$

is consumers' nominal income, $P_{k}$ is the price level consumers face in attention mode $k$, which satisfies

$C_{k} P_{k}=\int_{0}^{1} C_{k}(i) P_{k}(i) d i$,

and $k \in\{P A, Q A, P Q A, I A\}$.

The first order necessary conditions with respect to $C_{k}$ and $N_{k}$ respectively are:

$C_{k}^{-\sigma}=\lambda P_{k}$

and

$-N_{k}^{\varphi}=-\lambda \quad W$.

Dividing (25) by (24) and rearranging terms, we find that as long as the time constraint (18), is not binding, aggregate consumption is given by:

$C_{k}=\left(\frac{W}{P_{k}}\right)^{\frac{1}{\sigma}} N_{k}^{\frac{-\varphi}{\sigma}}$.

Substituting (26) in the budget constraint (17), we find that as long as the time constraint (18) is not binding, the time dedicated to labor $N_{k}$, is given by $\left(\frac{W}{P_{k}}\right)^{\frac{1-\sigma}{\varphi+\sigma}}$. If the time constraint is binding, consumers dedicate to labor all the time that they do not spend on processing goods' information. Thus,

$$
N_{k}=\left\{\begin{array}{ccc}
\left(\frac{W}{P_{k}}\right)^{\frac{1-\sigma}{\varphi+\sigma}} & \text { if } & \left(\frac{W}{P_{k}}\right)^{\frac{1-\sigma}{\varphi+\sigma}} \leq 1-\left(\delta_{p}(k) \tau_{p}+\delta_{Q}(k) \tau_{Q}\right) \\
1-\left(\delta_{p}(k) \tau_{p}+\delta_{Q}(k) \tau_{Q}\right) & \text { if } & \left(\frac{W}{P_{k}}\right)^{\frac{1-\sigma}{\varphi+\sigma}}>1-\left(\delta_{p}(k) \tau_{p}+\delta_{Q}(k) \tau_{Q}\right)
\end{array}\right.
$$


Consumers' nominal income (22), is therefore given by

$$
Y_{k}=\left\{\begin{array}{ccc}
W^{\frac{1+\varphi}{\varphi+\sigma}} P_{k}^{\frac{\sigma-1}{\varphi+\sigma}} & \text { if } & \left(\frac{W}{P_{k}}\right)^{\frac{1-\sigma}{\varphi+\sigma}} \leq 1-\left(\delta_{p}(k) \tau_{p}+\delta_{Q}(k) \tau_{Q}\right) \\
{\left[1-\left(\delta_{p}(k) \tau_{p}+\delta_{Q}(k) \tau_{Q}\right)\right] W} & \text { if } & \left(\frac{W}{P_{k}}\right)^{\frac{1-\sigma}{\varphi+\sigma}}>1-\left(\delta_{p}(k) \tau_{p}+\delta_{Q}(k) \tau_{Q}\right)
\end{array}\right.
$$

Since consumers spend all their income on consumption, aggregate consumption is equal to real income $\frac{Y_{k}}{P_{k}}$, and is therefore given by

$$
C_{k}=\frac{Y_{k}}{P_{k}}=\left\{\begin{array}{cc}
\left(\frac{W}{P_{k}}\right)^{\frac{1+\varphi}{\varphi+\sigma}} & \text { if }\left(\frac{W}{P_{k}}\right)^{\frac{1-\sigma}{\varphi+\sigma}} \leq 1-\left(\delta_{p}(k) \tau_{p}+\delta_{Q}(k) \tau_{Q}\right) \\
{\left[\begin{array}{c}
1-\left(\delta_{p}(k) \tau_{p}+\right. \\
\left.+\delta_{Q}(k) \tau_{Q}\right] \frac{W}{P}
\end{array}\right.} & \text { if }\left(\frac{W}{P_{k}}\right)^{\frac{1-\sigma}{\varphi+\sigma}}>1-\left(\delta_{p}(k) \tau_{p}+\delta_{Q}(k) \tau_{Q}\right)
\end{array}\right.
$$

Substituting (21), (27) and (29) in (1), we obtain the consumers' utility:

$$
\begin{aligned}
U_{k} & =\frac{1}{1-\sigma}\left(\frac{W}{P_{k}}\right)^{\frac{(1+\varphi)(1-\sigma)}{\varphi+\sigma}}-\frac{1}{1+\varphi}\left(\frac{W}{P}\right)^{\frac{(1+\varphi)(1-\sigma)}{\varphi+\sigma}} \\
& -\frac{\left(\delta_{p} \delta_{Q}(k) \tau_{Q} \frac{W}{P} \tau_{p}+\delta_{Q} \delta_{Q}(k) \tau_{Q} \frac{W}{P} \tau_{Q}\right)^{(1+\varphi)}}{1+\varphi}
\end{aligned}
$$

if

$$
\left(\frac{W}{P_{k}}\right)^{\frac{1-\sigma}{\varphi+\sigma}} \leq 1-\left(\delta_{p} \delta_{Q}(k) \tau_{Q}+\delta_{Q} \delta_{Q}(k) \tau_{Q}\right),
$$

and

$$
\begin{aligned}
U_{k} & =\frac{1}{1-\sigma}\left\{\left[1-\left(\delta_{p}(k) \tau_{p}+\delta_{Q}(k) \tau_{Q}\right)\right] \frac{W}{P_{k}}\right\}^{1-\sigma} \\
& -\frac{1}{1+\varphi}\left[1-\left(\delta_{p} \delta_{Q}(k) \tau_{Q} \frac{W}{P} \tau_{p}+\delta_{Q} \delta_{Q}(k) \tau_{Q} \frac{W}{P} \tau_{Q}\right)\right]^{(1+\varphi)} \\
& -\left(\delta_{p} \delta_{Q}(k) \tau_{Q} \frac{W}{P} \tau_{p}+\delta_{Q} \delta_{Q}(k) \tau_{Q} \frac{W}{P} \tau_{Q}\right)^{(1+\varphi)}
\end{aligned}
$$

if 
$\left(\frac{W}{P}\right)^{\frac{1-\sigma}{\varphi+\sigma}}>1-\left(\delta_{p} \delta_{Q}(k)+\delta_{Q} \delta_{Q}(k)\right)$.

Taking the nominal wage $W$, and the costs of processing goods' information $\tau_{P}$ and $\tau_{Q}$ as given, consumers choose the attention mode which maximizes their utility:

$$
\max U=\max \left\{U_{P A}, U_{Q A}, U_{P Q A}, U_{I A}\right\}
$$

Since all consumers are identical, all of them choose the same attention mode and therefore, all the consumers face the same price level.

\section{Calibration and Comparative Statics}

(i) Benchmark Economy

To study consumers' choices of attention modes, we calibrate the model for a benchmark economy and simulate it to study the effects of changes in the model's parameters. For the benchmark economy, we assume that the elasticity of marginal utility with respect to consumption, $-\sigma=-0.2$, and the elasticity of marginal disutility with respect to labor, $\varphi=0.1$. This implies that the marginal utility with respect to consumption decreases relatively slowly, and the marginal disutility with respect to labor increases almost linearly.

Following Barsky et al.’s (2003) findings, we set the elasticity of substitution between goods, $\varepsilon=11$ and therefore the markup, $\mu=\frac{\varepsilon}{\varepsilon-1}=1.1$. We normalize the nominal wage, $W$, the producers' expected marginal cost, $\Psi$, and the expected quantity per package, $Q^{e}$ to equal one.

Bils and Klenow (2004) and Nakamura and Steinsson (2008) report that the monthly frequency of consumers' goods' price changes is between $11 \%-25 \%$ per month. We therefore set the fraction of producers who experience marginal cost shocks and adjust their goods' prices, $\theta_{P}$, to 0.15 .

Following Gourville and Kohler (2004) who study changes in the prices and quantities of four goods and report that the monthly frequency of changes in quantities is between $2.7 \%$ and $8.2 \%$, we set the fraction of producers who experience marginal cost shocks and adjust their goods' quantities, $\theta_{Q}$, equal to 0.05 . 
We assume that half of the producers who experience a marginal cost shock experience a positive shock, $\eta_{h}>0$ and half experience a negative shock, $\eta_{l}<0$. In addition, we assume that $\eta_{h}=\left|\eta_{l}\right|$. Following Nakamura and Steinsson (2008) who report that most price changes are in the range of $10 \%-30 \%$, we set $\eta_{h}=\left|\eta_{l}\right|=0.15$.

Figure 1 divides the $\tau_{P}, \tau_{Q}$ space into four regions, indicating the combinations of the price information processing $\operatorname{cost}\left(\tau_{P}\right)$ and the quantity information processing cost $\left(\tau_{Q}\right)$ for which the consumers are: price attentive (PA), quantity attentive (QA), price and quantity attentive (PQA), and inattentive (IA). According to Figure 1, consumers are price and quantity attentive if both $\tau_{P}<0.024$ and $\tau_{Q}$ is in the range $0.05-0.08$. If $\tau_{P}>0.024$ and $\tau_{Q}>0.005$, consumers are inattentive. They are price attentive if $\tau_{Q}>0.008$ and $\tau_{P}<0.024$. They are quantity attentive if $\tau_{P}>0.024$ and $\tau_{Q}<0.005 .{ }^{9}$

Thus, consumers are inattentive even if the total cost of processing price and quantity information is relatively small and they are more likely to be price attentive than quantity attentive. There are two reasons for the last result. First, we assume that more producers adjust prices than quantities. Consequently, consumers have greater benefits from processing goods’ price- than quantity-information. Second, prices affect the utility gained from information processing because they appear in the budget constraint. Quantities affect the utility gained from information processing because they appear in the utility function. Prices, therefore, have greater effect than quantities on the utility gained from information processing because the coefficient of prices is one while the coefficient of quantities is less than 1.

The prediction that consumers are more likely to process price- than quantityinformation may explain Fox and Hoch’s (2005) finding that over 90 percent of consumers are price and quantity inattentive and almost all the rest are price attentive. This prediction is also consistent with Gourville and Kohler's (2004) finding that consumers are more likely to respond to price increases than to quantity decreases.

\footnotetext{
${ }^{9}$ Interpreting the time unit in the model as one month, with 4 weeks/month, 5 days/week, 16 hours/day for labor and leisure, and consumers make 8 shopping trips per month, consumers are price and quantity inattentive if processing goods' price and quantity information costs more than a total of 20-60 minutes. For example, when $\tau_{Q}=0.008$ and $\tau_{p}=0$, consumers need $0.008 \times 4 \times 5 \times 16 \times 60 \approx 160$ minutes/month for processing goods' information. With 8 shopping trips/month, they need $160 / 8=20$ minutes per shopping trip.
} 


\section{(ii) Changing the Elasticity of Marginal Utility}

Figure 2 shows the effect of increasing $-\sigma$ from -0.2 to -0.05 . We find that when consumers' elasticity of marginal utility with respect to consumption increases, consumers choose to process goods' price and quantity information for higher costs of information processing. The reason is that when $-\sigma$ increases, consumers obtain more utility from any given consumption bundle. Since they seek to increase their consumption, they are willing to dedicate more time and effort to processing goods' price and quantity information.

Figure 3 shows the effect of increasing $\varphi$, from 0.1 to 0.15 . When consumers' elasticity of marginal disutility with respect to labor increases, consumers choose to process goods' price and quantity information for higher costs of information processing. The reason is that as $\varphi$ increases, consumers lose more utility from any given amount of time they dedicate to labor. Thus, they are more willing to process price and quantity information because with lower prices they can increase consumption without dedicating more time to labor.

\section{(iii) Changing Consumers' Wage}

Figure 4 depicts the effect of decreasing the wage $(W)$ from 1 to 0.9 . Changing $W$ has two opposite effects on consumers' choices of attention mode. On the one hand, there is a negative substitution effect, because when $W$ increases, time becomes more valuable. On the other hand, there is a positive income effect, because when $W$ increases, consumers can purchase more packages, and therefore their benefits from lower price level increase. Thus, the total effect of the change in the consumers' wage is ambiguous and cannot be predicted. Simulations using different values of $W$ suggest that when consumers' income decreases, the positive income effect usually dominates the negative substitution effect. Low-income consumers are, therefore, more likely to process goods' price and quantity information than consumers with average incomes, which is consistent with the findings reported by Gabor and Granger $(1961,1966)$ and more recently by Falkinger (2008). The simulation results also suggest that high income consumers may be more or less likely than the average consumers to process goods' price and quantity information. ${ }^{10}$

\footnotetext{
${ }^{10}$ Hoch et al. (1995) indeed find that income has an ambiguous effect on the price elasticity of food and cleaning detergents.
} 


\section{(iv) Changing the Fraction of Producers Who Adjust Goods' Price and Quantity}

Figures 5 and 6 depict the effects of increasing the shares of producers who adjust prices, $\theta_{P}$, and quantities, $\theta_{Q}$. In Figure $5, \theta_{P}$ is increased from 0.15 to 0.25 while in Figure 6, $\theta_{Q}$ is increased from 0.05 to 0.2 . The effects in both cases are similar. When the fraction of producers who adjust their goods' prices, $\theta_{P}$, or quantities, $\theta_{Q}$, increases, consumers become price and quantity attentive for larger costs of processing goods' price and quantity information. The reason is that when the fraction of producers who adjust either their goods' prices or quantities increases, the variance of goods' unitprices, $\operatorname{Var}\left[\frac{P(i)}{Q(i)}\right]$, increases and thus consumers have greater incentives to process goods’ price and quantity information.

\section{(v) Changing the Elasticity of Substitution between Goods}

Figure 7 depicts the ceteris paribus effect of increasing the elasticity of substitution $\varepsilon$, from 11 to $21 .{ }^{11}$ When $\varepsilon$ increases, consumers become price and quantity attentive for larger costs of processing goods' price and quantity information. The reason is that when $\varepsilon$ increases, consumers are more willing to substitute high unit-price goods with low unit-price goods and, therefore, their benefits from processing goods' unitprices increase.

\section{(vi) Changing the Expected Marginal Cost}

Increasing the expected marginal cost $\Psi$, leads to a proportional increase in the expected unit-price of all goods. This has two opposite effects on consumers' choices of attention modes. On the one hand, higher expected unit-price has a negative income effect, because an increase in the average price reduces the real income. On the other hand, increasing the expected price while holding the size of the marginal cost shocks unchanged reduces the substitution effect, because the relative differences between goods that their price differs from the expected price and goods that their prices equal the expected price become smaller. Thus, the total effect of an increase in $\Psi$ is ambiguous. For example, holding everything else the same as in the benchmark economy, as long as $\Psi$ is between 1 and 2.5 consumers process goods’ price and quantity information only

\footnotetext{
${ }^{11}$ Without the ceteris paribus constraint, an increase in the elasticity of substitution from 11 to 21 would have caused producers to reduce their markups from 1.1 to 1.05 .
} 
for smaller costs of information processing than in the benchmark economy. If $\Psi>2.5$, as in Figure 8 where $\Psi=3$, the income effect dominates and consumers are price and quantity attentive for larger costs of processing goods’ price and quantity information than consumers in the benchmark economy.

\section{(vii) Changing the Expected Quantity}

Figure 9 depicts the effect of an increase in goods' expected quantity, $Q^{e}$, from 1 to 1.5 . When $Q^{e}$ increases, consumers become price and quantity attentive for larger costs of processing goods' price and quantity information. The reason is that when $Q^{e}$ increases, consumers receive more utility from each package they purchase. Consequently, they have greater incentives to process goods’ price and quantity information.

\section{(viii) Changing the Size of the Marginal Cost Shock}

Figure 10 depicts the effect of an increase in the absolute value of the marginal cost shocks from $|\eta|=0.15$ to $|\eta|=0.2$. When $\left|\eta_{h}\right|$ and $\left|\eta_{l}\right|$ increase, consumers become price and quantity attentive for larger costs of processing goods' price and quantity information. The reason is that when $\left|\eta_{h}\right|$ and $\left|\eta_{l}\right|$ increase, the variance of goods' unitprices increases. Consumers, therefore, lose more utility if they do not process either goods’ price or quantity information.

\section{Data}

Our data comes from two surveys conducted in Israel during 2005-2008. In the first survey, we sampled consumers in two supermarkets (supermarkets 1 and 2 in Table 1) and in the second, in 13 supermarkets (supermarkets 3-15 in Table 1). 11 of the 15 supermarkets belong to large national chains and the rest are either unaffiliated or affiliated with local chains.

The supermarkets are located in 7 cities. About half of the supermarkets are discount supermarkets which offer lower prices, lower quality of services and usually carry fewer brands than other supermarkets. Some information about the supermarkets and the consumers who live in the cities where they are located is given in Tables 1-3. 
During the survey period, the Israeli GDP grew at an annual rate of 4\%-6.5\%. ${ }^{12}$ The annual inflation during 2005-2007 was between 0\%-2\%. It increased to 3.7\% in 2008. ${ }^{13}$

In both surveys, consumers were approached as they came out of supermarkets, immediately after they finished their shopping. The theory of retrieval cues (Laibson, 2001, Smith et al., 2003) suggests that consumers are more likely to succeed in retrieving information about goods' prices and quantities at the exit from supermarkets than in other places because there they usually have more retrieval cues. ${ }^{14}$

Consumers who agreed to participate were first asked about their socio-economic status and then they were shown a list of goods. ${ }^{15}$ Out of these goods, consumers were asked only about goods they purchased in their current shopping trip. The consumers usually needed about five minutes to answer all the questions.

The first survey was conducted before, during and after the Passover holiday in April-May 2005. In that survey, the list of goods included 10 goods that were sold at a price discount, 10 goods that were sold at a quantity discount, and 10 goods that were sold at their list prices. ${ }^{16}$ For each supermarket, the lists were updated each week because some of the goods changed their discount status after one or two weeks. Consumers were asked whether or not the goods from the list which they have purchased were offered at a discount and which type of discount it was (if any). Table 4 gives information about the sampled goods.

The second survey was conducted as follows: in Supermarkets 3-5 during AprilJuly 2006, in Supermarkets 6-9 during April-July 2007 and in Supermarkets 10-15 during April-October 2008. The lists consumers were shown contained goods belonging to one of 17 categories, which represent a large proportion of the goods sold in Israeli supermarkets. Table 5 offers the list of categories. It also offers summary statistics of the goods that were sampled in Supermarket $3 .^{17}$

\footnotetext{
${ }^{12}$ Source: www.cbs.gov.il/shnaton60/st14_02x.pdf.

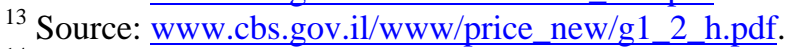

${ }^{14}$ We were not allowed to interview them inside the supermarkets.

${ }^{15}$ We asked about $30 \%$ of the subjects on their socio-economic status after they finished the main part of the questionnaire. This did not significantly affect the responses.

${ }^{16}$ An example of a price discount is a 6-pack of 1.5L bottles of Pepsi sold for NIS 21.89 instead of the list price of NIS 26.40 (i.e., a lower price for the same quantity). An example of a quantity discount is CocaCola sold in bottles of 1.75L instead of the standard 1.5L for the same price (i.e., a higher quantity for the same price). "Value packs" and "Bonus packs" sometimes offered by US retailers is an example of a quantity discount.

${ }^{17}$ We present Supermarket 3 data as an example because the frequency of price changes in Supermarket 3 is similar to the one we find in many of the other supermarkets in the dataset.
} 
Consumers were asked to recall the prices and quantities of the goods i they have purchased from the list. They were also asked about purchase frequency of the goods, about the number of packages they purchased in the current shopping trip, about consumption frequency of these goods, and whether the goods are usually consumed by themselves, by their spouses, by their children or by their friends and relatives. ${ }^{18}$

\section{Empirical Tests and Estimation Results}

\section{(i) Test 1: Consumers' Attention to Goods’ Prices and Quantities}

In the second survey, consumers exiting supermarkets were asked to recall the prices and quantities of goods that they bought. The psychology literature on depth of processing and memorizing techniques suggests that the probability of successfully storing and recalling information is correlated with the time and effort dedicated to processing it (Smith, et al., 2003, p. 278). We therefore use the errors that consumers make in recalling price and quantity information as a proxy for the time and effort they devote to processing goods’ price and quantity information (Vanhuele and Drèze, 2002).

The mean absolute price error in our sample is 33\%, which is similar to the figure reported by Vanhuele and Drèze (2002). The mean absolute quantity error, however, is close to $450 \%$, which suggests that consumers have difficulty in processing quantity information. One possible reason is that processing quantity information requires understanding of measurement units. Math performance studies of US students, however, show that more than 50 percent fail in questions on measurement units. ${ }^{19}$ A second possible reason is that often it is easier to find price information than quantity information. Some consumers, therefore, might look for price but not for quantity information (Miyazaki et al., 2000).

Following the model, we assume that the likelihood of correctly recalling goods' price and quantity information depends on consumers’ and goods' attributes and on market conditions. Because we are interested in consumers' knowledge of both prices and quantities, we estimate two regressions. In one, the dependent variable is the absolute percentage error that consumers make in recalling goods’ price information. In the second, the dependent variable is the absolute percentage error made in recalling quantity information. Because the errors in recalling the price and quantity information of the

\footnotetext{
${ }^{18}$ The survey was conducted in Hebrew. An English version of the questionnaire is available upon request.

${ }^{19}$ Source: www.k12.wa.us/research/pubdocs/pdf/mathbook.pdf. See also the discussion on the failure of the metric education system in the UK and its possible implications for consumers: www.bwmaonline.com/The\%20Failure\%20of\%20Metrication\%20by\%20Education.htm.
} 
same good might be correlated, we use the SUR approach. In both regressions, we include the same set of independent variables: A gender dummy (1 if a consumer is a woman), an education dummy (1 if a consumer has an academic degree), a large family dummy ( 1 if a consumer's family has more than five members), a religion dummy (1 if a consumer defines himself as moderately religious), a discount supermarket dummy (1 if it is a discount supermarket), a location dummy (1 if a supermarket is located outside a city), a duration dummy ( 1 if the good is consumed within a short period), a package dummy (1 if a good is sold in multi-unit packages), the goods' price and quantity as recalled by the consumer, the category-level average price and the average quantity, the category-level standard deviation of prices and quantities, the year 2008 dummy, a holiday dummy ( 1 if a good was purchased during a holiday period) and fixed effects for goods' categories, for consumers' age groups and for the cities where the supermarkets are located. ${ }^{20}$

We do not have any specific hypothesis about the gender dummy, and we include it to avoid missing variables bias. We expect that subjects with academic background have lower information processing costs, because evidence from psychology literature suggests that the ability to obtain higher education is correlated with better memorization and retrieval skills (Dehn, 2008). We expect consumers with large households to have greater benefits from processing price and quantity information because such consumers often need to buy large quantities of each good. They, therefore, pay a higher premium if they choose brands with a high unit price than consumers with smaller households. Consumers with a moderate-Jewish religious background often purchase only goods that satisfy strict Kosher requirements than secular consumers. Therefore, brands that satisfy religious consumers’ Kosher requirements often have greater market power among religious consumers than among the general population. The discussion following Figure 7 suggests, therefore, that religious consumers will tend to be less likely to process goods' price and quantity information. We expect that consumers who shop in discount supermarkets are likely to have lower opportunity cost of time and tighter budget constraints than consumers who shop in more expensive locations. We therefore expect consumers shopping in discount supermarket to be more likely to process goods’ price and quantity information. We do not have a priori expectations about consumers who

\footnotetext{
${ }^{20}$ We also added a variable for the consumers' average expenditure, but it was insignificant in both this and the regression reported in section (ii), perhaps because we used relatively large expenditure brackets in the survey, and consequently much of the variance between consumers was lost.
} 
shop in supermarkets located outside cities, because although such supermarkets tend to be discount supermarkets, they often appeal mostly to consumers who work outside the city and who shop on their way home.

If goods are consumed within a short period, consumers will have greater benefits from knowing their prices and quantities. Thus, we expect that consumers are more likely to correctly recall the prices and quantities of such goods. Goods sold in multi-unit packs offer greater quantity per package and, therefore, consumers have greater incentives to process their price and quantity information. However, it is also harder to process the quantities of multi-unit packs because the calculation involves a multiplication operation. ${ }^{21}$ It might be, therefore, that consumers are more likely to correctly recall multi-unit packs' prices, but it is harder to make ex-ante predictions about whether or not they are more likely to correctly recall their quantities.

Evidence from marketing literature suggest that consumers form reference prices for product categories, and that these reference prices depend either on the recalled prices of selected brands (internal reference prices) or on the average price in the category (external reference price). According to this literature, consumers tend to choose brands that offer them the lowest price relative to the reference price rather than the brands that offer them the lowest absolute prices (Kalyanaram and Winer, 1995, Mazumdar and Papatla, 2000). We therefore include in the regression, goods' recalled prices and quantities together with the average prices and quantities in the category to avoid a missing variables bias. $^{22}$

The model suggests that an increase in the variance of goods' prices and quantities will make consumers more likely to process the price and quantity information. Increasing the standard deviation, however, also increases the cost of processing price and quantity information because there is more information to process. The findings by Krieder and Han (2004) suggest that an increase in the variance of prices will make consumers more likely to correctly recall the price information. They, however, do not estimate the effect of an increase in the standard deviation of quantities.

The inflation in Israel was 3.7 percent in 2008, whereas during earlier years the it hovered around 0 percent. 2008 was also a year of economic slowdown and, therefore, many consumers experienced a decrease in their incomes. We therefore include a 2008

\footnotetext{
${ }^{21}$ For example, the quantity of a 6 -pack of Pepsi ( $16 \mathrm{fl}$ oz per bottle) is $6 \times 16=96 \mathrm{fl} \mathrm{oz}$.

${ }^{22}$ We find that omitting these variables affects the significance of some of the other variables but it usually has only a small effect on the size of the coefficients.
} 
dummy to control for these two effects. Because moderate inflations are often associated with an increase in the share of producers who adjust prices, the discussions following Figure 4, 5 and 6 suggest that in 2008 consumers should be more likely to devote time and cognitive effort to processing goods' price and quantity information than in 2006 and 2007 (Gagnon, 2009).

As discussed above, consumers are likely to have greater marginal benefits from consumption in holidays than in other times because they have more leisure and also because consumption in holidays often takes place in social settings. Thus, the discussion following Figure 2 suggests that during holidays, consumers should be more likely to process goods' price and quantity information.

Because the dependent variables are the absolute percentage errors that consumers make, negative coefficients indicate smaller errors. We, therefore, expect that the variables that increase consumers' benefit from information processing, will attain negative coefficients in both regressions, while the variables that increase the costs of information processing will attain positive coefficients. In addition, we expect that variables that affect the costs side, will have stronger effects in the quantity regression than in the price regression because the discussion above suggests that the cost of processing quantity information is greater, and the evidence suggest that large cognitive costs affect behavior more than small costs (Kahneman and Frederick, 2002, p. 68).

The estimation results are reported in Table 6. The coefficients of Woman are positive and significant in both regressions. Thus, in our data, men tend to make smaller errors than women. ${ }^{23}$ As expected, academics tend to make smaller errors than nonacademics and the effect is significant for the cognitively more difficult task of recalling quantity information. It is not significant for recalling price information.

As expected, the coefficients of large families are negative. However, we find that the coefficients are statistically insignificant, perhaps because the low variance of family sizes in our sample: The largest families have 6 members and the average families have almost 4 members.

The discussion above suggests that moderately religious consumers should be less likely to process goods’ price and quantity information. We find that they are indeed more likely to make larger errors in recalling quantity information, but there are no

\footnotetext{
${ }^{23}$ Marketing studies suggest that women pay more attention than men to prices (Raajpoot, et al. 2008). However, modern social trends are altering the traditional roles-and consequently the shopping behavior — of men and women (Mortimer, 2009).
} 
statistically significant differences between the errors they and non-religious consumers make in recalling price information.

Almost opposite results are obtained for consumers who shop at discount supermarkets. The discussion above suggests that they should devote more time to processing goods' price and quantity information. The results suggest that they make smaller errors in recalling quantity information, but there are no statistically significant differences between the errors they and other consumers make in recalling price information.

Above we hypothesized that consumers will have greater incentives to process the price and quantity information of goods they consume within a short period. The results suggest that they are indeed more likely to correctly recall the price information of such goods. At the same time, there are no statistically significant differences between the likelihood they correctly recall the quantity of goods consumed within a short period and other goods. Thus, consumers seem to have greater incentives to process the price and quantity information of goods they consume within a short period and these incentives are great enough to affect the likelihood of correctly storing and recalling prices, but not enough to affect the likelihood of correctly storing and recalling quantities.

The discussion above suggests that consumers should be more likely to recall the prices of multi-unit packages than single unit packages. The coefficient of multi-unit packages in the price errors equation is indeed negative and significant. The discussion above also suggests that it is harder to predict the effect of multi-unit packages on the likelihood of correctly recalling the quantity information because processing the quantity information of multi-unit packs is more beneficial than single-unit packs but it is also cognitively more demanding. The results suggest that for most consumers, the greater difficulty is more important than the greater benefits.

The coefficients of categories' average prices and categories average quantities are negative, whereas the coefficients of the recalled price and recalled quantities are positive, suggesting that consumers in our sample use external reference prices. The positive effects of recalled prices and quantities suggest that as goods’ prices and quantities increase, so do the range of possible errors.

The discussion above suggests that consumers should be more likely to recall goods price and quantity information in 2008 than in 2006 and 2007 because the inflation was higher and consumers' income was often lower in 2008 than in 2006 and 2007. 
Consistent with these predictions, the coefficients of the 2008 dummy are negative in both regressions.

The holiday coefficients are negative in both regressions, suggesting, as discussed above, that consumers have higher marginal utility from consumption in holidays, and therefore, they are more likely to process price and especially quantity information.

\section{(ii) Test 2: Consumers’ Attention to Price and Quantity Discounts}

Some authors criticize the use of price recall information as a proxy for the knowledge that consumers have about goods' prices because price recall surveys ask for information that consumers might store in non verbal code and therefore, consumers might fail to give correct answers even if they know them (Monroe and Lee, 1999, Vanhuele and Dréze, 2002). ${ }^{24}$ We, therefore, use data from the first survey to study the likelihood that consumers correctly recall whether or not goods are offered at a discount. This offers a more conservative test than the one reported in section (i) for several reasons. First, the gains from processing discount information can be large. ${ }^{25}$ Second, discount information is usually more visible and therefore, easier to process than other types of price and quantity information. Third, recalling whether or not a good is sold at a discount involves only a yes-or-no answer, and therefore it is easier to recall than the goods’ exact price and quantity (Monroe and Lee, 1999, Vanhuele and Drèze, 2002). Indeed, we find that consumers correctly recall whether or not a good is offered at a discount in about 70\% of the cases, whereas Vanhuele and Dréze (2002) report that only about $2 \%$ of the consumers correctly recall goods' exact prices.

Following our model, we assume that the likelihood that consumers correctly recall goods’ price and quantity information depends on their choice of attention mode and on goods' attributes. We further assume that consumers choose between two attention modes, attentive and inattentive, and that attentive consumers are more likely to recall whether or not a good is offered at a discount. In addition, we assume that goods' attributes have the same effect on both types of consumers. Following Gupta and

\footnotetext{
${ }^{24}$ According to cognitive psychologists there are two ways of storing information in memory. Explicit memory is for storing information used verbally. Implicit memory is for storing information used in nonverbal settings, e.g., riding a bike (Smith et al. 2003, p. 269). Monroe and Lee (1999) suggest that asking consumers to give verbal responses to questions about goods' prices might underestimate their knowledge, because they likely use non-verbal code to store information in long-term memory. They argue that because price information is used for internal comparisons, it is likely to be stored in implicit memory and consequently, consumers are likely to find it difficult to recall them verbally.

${ }^{25}$ The average discount at the two supermarkets surveyed was $15 \%-20 \%$ of the list prices.
} 
Chintagunta (1994), we use a logistic mixture model to simultaneously estimate the effects of the consumers' and goods' attributes. Thus, we maximize: ${ }^{26}$

$$
\begin{aligned}
& \log (L)=\sum_{i=1}^{N} \log \left[P\left(\text { Consumer with attributes } X_{i} \text { chose mode } k\right) \times\right. \\
& \left.P\left(\text { The consumer gave response } c \text { when the purchased good has attributes } Z_{j}\right)\right]
\end{aligned}
$$

where $L$ is the likelihood function, $N$ is the number of consumers, $P$ is the logistic probability function, $k \in\{$ attentive, inattentive $\}, c \in\{$ correct, incorrect $\}, X_{i}$ is the set of attributes of consumer $i$, and $Z_{j}$ is the set of attributes of good $j$.

We assume that consumers' attributes $X$, include the following dummy variables: woman, academic degree, large family, moderately religious, age (1 if a consumer is 4555 years old), cashier-parking (1 if a consumer answered that both the number of cashiers and the availability of parking are very important to him), and Passover (1 if the observation was collected during the Passover holiday). ${ }^{27}$

We hypothesize that the effect of woman, academic degree, large family and moderately religious variables will be similar to what we discussed in section (i). We include the age variable because empirical results suggest that consumers in the 40-55 age group are more likely than other consumers to correctly recall goods' prices (Fox and Hoch, 2005). We include the cashier-parking variable because consumers who care more about the number of parking places and the number of cashiers are more likely to be time constrained. We, therefore, expect such consumers to devote less time and cognitive effort to processing goods’ price and quantity information. We include the Passover variable because it is one of the main holidays in the Jewish calendar, and the main family get-together event. The discussion above suggests, therefore, that consumers should have high marginal utility of consumption in Passover and should therefore be more likely to process goods’ price and quantity information.

We assume that goods' set of attributes, $Z$, include the following dummy variables: discount ( 1 if the discount $<10$ percent), supermarket 2 ( 1 if the good was purchased at supermarket 2 and 0 if it was purchased at supermarket 1), price discount (1 if a good was offered at a price discount), quantity discount (1 if a good was offered at a quantity discount), and interactions of the Passover dummy and "more than NIS 20"

\footnotetext{
${ }^{26}$ We have tried logit and multi-logit specifications as well. In all cases, we obtained similar results.

${ }^{27}$ We also estimated the regression with dummies for different age-groups. The results were similar to what we report here.
} 
dummy (1 if a good costs NIS 20 or more), price discount and quantity discount. ${ }^{28}$ We also include fixed effects for goods' categories, to control for variation in the market structure.

We include the discount variable because the model suggests that consumers are less likely to process goods’ price and quantity information if the benefit from doing so is relatively small. In edition, empirical evidence suggests that consumers are less likely to process information about small discounts than about larger ones (Krieder and Han, 2004, Chen et al., 2008). Supermarket 1 is a discount supermarket whereas Supermarket 2 is located in a high income neighborhood. The price and quantity information of brands offered in Supermarket 2 are, therefore, less likely to be processed than these of the same brands in Supermarket 1. Price and quantity discounts control for whether a good was offered at a price or a quantity discount. Their coefficient can indicate which type of a discount is more likely to be processed and correctly recalled by consumers. We expect that because processing price information is easier than processing quantity information, consumers should be more likely to recall price discounts than quantity discounts.

The model predicts that holding the relative size of price changes the same, consumers should be more likely to process goods' price and quantity information if the goods' prices are high. We expect, therefore, that the coefficient of the interaction term of more than NIS 20 and Passover is positive, i.e., consumers are more likely to process goods' information if the goods are relatively expensive.

We include the interaction terms of Passover and the price and quantity discounts because the model suggests that during holidays consumers should dedicate more time and cognitive effort to processing goods’ price and quantity information. These interaction terms control for any changes in the likelihood that consumers correctly recall price and quantity discounts during Passover period relative to other periods.

The results of the maximum likelihood estimation of (32) are reported in Table 7 along with robust standard errors. The coefficients of woman and academic degree are not significant, although their signs are consistent with the regression in section (i). As expected, the coefficient of large families is positive and significant.

\footnotetext{
${ }^{28}$ We chose to define goods costing more than NIS 20 (about \$5)as “expensive” because NIS 20 is about double the average cost of a good in a supermarket in the sample period (source: www.cbs.gov.il/reader/?MIval=/prices_db/). The coefficient of the main effect of "costs NIS 20 or more" is statistically insignificant and has no significant effect on other coefficients. We therefore dropped it from the regression.
} 
Consumers in the 45-55 age group are, as predicted above, more likely than consumers of other age to correctly recall discounts. As predicted, moderately religious consumers are less likely to correctly recall discounts. Also as predicted above, the coefficient of the Passover dummy is positive and significant. Thus, consumers are more likely to recall whether or not goods are offered at a discount if they are shopping during the Passover period than in other times. ${ }^{29}$

There is an alternative explanation, however. During Passover there are more discounts than during other times, and therefore they are more noticeable. To account for this, we take advantage of the fact that most discounts start one week before the Passover holiday and last one week beyond Passover. If consumers are more attentive to discounts because they are more noticeable, then consumers should be equally likely to recall whether or not a good is offered at a discount during all weeks. On the other hand, if consumers are more likely to recall discounts only when they have high marginal utility of consumption, they will be more likely to recall discounts only during Passover.

We use ANOVA to compare the likelihood that consumers correctly recall whether or not goods are offered at a discount during these three weeks. We find no statistical differences between the probability of correctly recalling discounts in the weeks before and after Passover $(F=0.14, p>0.7)$, but the probability of correctly recalling discounts during the week of the holiday is significantly greater than in the weeks before $(F=32.65, p<0.01)$ and after the holiday $(F=19.33, p<0.01)$. This suggests, therefore, that the increase in the likelihood of correctly recalling discounts is due to higher marginal utility of consumption and not due to the higher salience of the discounts. Thus, the results for the consumers' attributes are consistent with our predictions, and reiterates the results obtained in section (i).

The effects of goods' attributes are as follows. As predicted above, consumers are less likely to recall discounts of 10 percent or less. They are also less likely to recall discounts if they shop at the expensive supermarket 2.

The coefficient of the interaction of holiday and costs NIS 20 or more is positive and significant, suggesting that, as discussed above, consumers are more likely to process the price and quantity information of more expensive goods.

The coefficients of both price discount and quantity discount are positive and significant. However, the coefficient of price discount is significantly greater than the

${ }^{29}$ The Passover period in Israel is similar to the Christmas period in the US (Warner and Barsky, 1995, Chevalier et al., 2003, Levy et al., 2010). 
coefficient of quantity discount $\left(\chi_{(1)}^{2}=3.17, p<0.1\right.$ ), which suggests that during nonholidays consumers are more likely to process goods' price information than quantity information. During holidays, however, the interaction of holiday and price discount is insignificant, whereas the interaction of holiday and quantity discount is positive and significant. Thus, during holidays consumers are marginally more likely to recall quantity discounts than price discounts $\left(\chi_{(1)}^{2}=3.51, p<0.1\right)$. This may explain why producers in Israel are more likely to offer quantity discounts in Passover and other major holidays than in other times. Indeed we find that during the sample period, almost half of the discounts offered during the Passover period at both supermarkets were quantity discounts compared with a much smaller proportion in other periods.

\section{Conclusions}

According to Swan's (1970) theorem, consumers should be indifferent between price and quantity adjustments as long as the unit-prices are the same. Empirical evidence, however, suggests that consumers often respond to price adjustments differently than to quantities adjustments. In this paper we construct, calibrate, and test a model that offers a possible explanation for this finding. In the model, consumers face cognitive information processing costs and have to choose whether to process goods' price information, goods' quantity information, both or neither.

We test the model's predictions using data from two surveys we conducted in Israel on the information consumers have about goods' prices and quantities. The model and the empirical findings suggest that information processing costs and consumers' needs determine the information that consumers have on goods' prices and quantities.

Therefore, information processing costs might have important implications for both micro- and macro-economic outcomes. For example, Carlton (1989, 1991), Gabaix and Laibson (2006), Levy et al. (2010) and Armstrong and Chen (2009) suggest that if producers have more information than consumers about goods' attributes, then they may use non-price (rather than price) adjustment mechanisms and, consequently, the market may reach a new equilibrium even if prices remain unchanged.

In addition, there is empirical evidence suggesting that the knowledge consumers have about goods' prices can affect inflation and output, especially if, as predicted by our model, this knowledge changes over time and across economic conditions (Konieczny, 1993, Warner and Barsky, 1995). 
More work is needed to asses the empirical relevance of cognitive processing costs for consumers' behavior, and for understanding the responses of producers and consumers to changes in these costs (Rotemberg, 1983, 2005, Gabaix et al., 2006). More research is needed also to better understand consumers' responses to quantity decreases, because the anger that consumers often express when they discover a quantity decrease, can affect the long-term relationship between producers and consumers (Blinder et al., 1998, Rotemberg 2005). Studying the relevance of our findings for other non-price adjustment mechanisms such as quality adjustments (e.g., Armstrong and Chen, 2009) can also be fruitful. 


\section{APPENDIX}

\section{Demand of Price Attentive Consumers and the Price Level They Face}

Price attentive consumers process all goods’ price information but they assume that all goods' quantity per package equal the expected quantity per package $Q^{e}$. For a given income, maximizing utility is equivalent to maximizing the consumption bundle. Price Attentive consumers, therefore, choose $C_{P A}(i)$ for all $i \in(0,1)$ which maximizes $C_{P A}=\left\{\int_{0}^{1}\left[C_{P A}(i) Q^{e}\right]^{\frac{\varepsilon-1}{\varepsilon}} d i\right\}^{\frac{\varepsilon}{\varepsilon-1}}$, subject to the income constraint: $\int_{0}^{1} C_{P A}(i) P(i) d i=Y_{P A}$.

Denoting the Lagrange multiplier with $\lambda$, the Lagrangian is given by $\ell=\left\{\int_{0}^{1}\left[C_{P A}(i) Q^{e}\right]^{\frac{\varepsilon-1}{\varepsilon}} d i\right\}^{\frac{\varepsilon}{\varepsilon-1}}+\lambda \int_{0}^{1}\left[Y_{P A}-C_{P A}(i) P(i)\right] d i$

Differentiating (A1.2) with respect to $C_{P A}(i)$ and setting the result equal to zero, yields:

$$
\left\{\int_{0}^{1}\left[\left[C_{P A}(i) Q^{e}\right]^{\frac{\varepsilon-1}{\varepsilon}} d i\right]\right\}^{\frac{\varepsilon}{\varepsilon-1}-1}\left[C_{P A}(i) Q^{e}\right]^{\frac{-1}{\varepsilon}} Q^{e}=\lambda P(i)
$$

Differentiating with respect to $C_{P A}(j)$ and setting the result equal to zero yields

$$
\left\{\int_{0}^{1}\left[\left[C_{P A}(i) Q^{e}\right]^{\frac{\varepsilon-1}{\varepsilon}} d i\right]\right\}^{\frac{\varepsilon}{\varepsilon-1}-1}\left[C_{P A}(j) Q^{e}\right]^{\frac{-1}{\varepsilon}} Q^{e}=\lambda P(j)
$$

Dividing (A1.3) by (A1.4) yields:

$$
\left[\frac{C_{P A}(j)}{C_{P A}(i)}\right]^{\frac{1}{\varepsilon}}=\frac{P(i)}{P(j)}
$$


Thus, the consumption of good $j$ as a function of the consumption of good $i$ is given by:

$C_{P A}(j)=\left[\frac{P(i)}{P(j)}\right]^{\varepsilon} C_{P A}(i)$

Using (A1.6) to substitute for the consumption of each good $j \in(0,1)$ in the budget

constraint (A1.1), we obtain:

$\int_{0}^{1}\left[\frac{P(i)}{P(j)}\right]^{\varepsilon} C_{P A}(i) P(j) d j=Y_{P A}$

Rearranging the LHS yields:

$C_{P A}(i) P(i)^{\varepsilon} \int_{0}^{1} P(j)^{1-\varepsilon} d j=Y_{P A}$

Therefore,

$C_{P A}(i)=\frac{Y_{P A}}{P(i)^{\varepsilon} \int_{0}^{1} P(j)^{1-\varepsilon} d j}=\left[\frac{P(i)^{-\varepsilon}}{\int_{0}^{1} P(j)^{1-\varepsilon} d j}\right] Y_{P A}$.

The price index that price attentive consumers face is defined by:

$C_{P A} P_{P A}=\int_{0}^{1} C_{P A}(i) P(i) d i$

where $C_{P A}$ is the aggregate consumption bundle of price attentive consumers. It is

defined by $C_{P A}=\left\{\int_{0}^{1}\left[C_{P A}(i) Q(i)\right]^{\frac{\varepsilon-1}{\varepsilon}} d i\right\}^{\frac{\varepsilon}{\varepsilon-1}}$. We use some good $i \in(0,1)$ as a

numeraire and we use (A1.6) to substitute for the consumption of every good $j \in(0,1)$ in both sides of (A1.10). Doing so yields:

$$
\left[\int_{0}^{1}\left[C_{P A}(i)\left[\frac{P(i)}{P(j)}\right]^{\varepsilon} Q(j)\right]^{\frac{\varepsilon-1}{\varepsilon}} d j\right]^{\frac{\varepsilon}{\varepsilon-1}} P_{P A}=\int_{0}^{1} C_{P A}(i)\left[\frac{P(i)}{P(j)}\right]^{\varepsilon} P(j) d j
$$

Dividing both sides of (A1.11) by $C_{P A}(i)$ and $P(i)^{\varepsilon}$ we obtain: 


$$
\left[\int_{0}^{1} P(j)^{1-\varepsilon} Q(j)^{\frac{\varepsilon-1}{\varepsilon}} d j\right]^{\frac{\varepsilon}{\varepsilon-1}} P_{P A}=\int_{0}^{1} P(j)^{1-\varepsilon} d j
$$

Thus, the price level price attentive consumers face is given by:

$$
P_{P A}=\frac{\int_{0}^{1} P(j)^{1-\varepsilon} d j}{\left[\int_{0}^{1} P(j)^{1-\varepsilon} Q(j)^{\frac{\varepsilon-1}{\varepsilon}} d j\right]^{\frac{\varepsilon}{\varepsilon-1}}}
$$

\section{Demand of Quantity Attentive Consumers and the Price Level They Face}

Quantity attentive consumers process all goods’ quantity per package information but they assume that all goods' prices equal the expected price $P^{e}$. They, therefore, choose $C_{Q A}(i)$ for every $i \in(0,1)$ which maximizes $C_{Q A}=\left\{\int_{0}^{1}\left[C_{Q A}(i) Q(i)\right]^{\frac{\varepsilon-1}{\varepsilon}} d i\right\}^{\frac{\varepsilon}{\varepsilon-1}}$ subject to the budget constraint $\int_{0}^{1} C_{Q A}(i) P^{e} d i=Y_{Q A}$

Denoting the Lagrange multiplier with $\lambda$, the Lagrangian is given by

$$
\ell=\left\{\int_{0}^{1}\left[C_{Q A}(i) Q(i)\right]^{\frac{\varepsilon-1}{\varepsilon}} d i\right\}^{\frac{\varepsilon}{\varepsilon-1}}+\lambda \int_{0}^{1}\left[Y_{Q A}-C_{Q A}(i) P^{e}\right] d i
$$

Differentiating (A2.2) with respect to $C_{Q A}(i)$, and setting the result equal to zero yields: 


$$
\left\{\iint_{0}^{1}\left[C_{Q A}(i) Q(i)\right]^{\frac{\varepsilon-1}{\varepsilon}} d i\right\}^{\frac{\varepsilon}{\varepsilon-1}-1}\left[C_{Q A}(i) Q(i)\right]^{\frac{-1}{\varepsilon}} Q(i)=\lambda P^{e}
$$

Differentiating (A2.2) with respect to $C_{Q A}(j)$ and setting the result equal to zero yields:

$$
\left\{\int_{0}^{1}\left[C_{Q A}(i) Q(i)\right]^{\frac{\varepsilon-1}{\varepsilon}} d i\right\}^{\frac{\varepsilon}{\varepsilon-1}-1}\left[C_{Q A}(j) Q(j)\right]^{\frac{-1}{\varepsilon}} Q(j)=\lambda P^{e}
$$

Dividing (A2.3) by (A2.4) yields:

$$
\left[\frac{C_{Q A}(j)}{C_{Q A}(i)}\right]^{\frac{1}{\varepsilon}}\left[\frac{Q(i)}{Q(j)}\right]^{\frac{\varepsilon-1}{\varepsilon}}=1
$$

Rearranging terms, we find that:

$$
C_{Q A}(j)^{\frac{1}{\varepsilon}}=C_{Q A}(i)^{\frac{1}{\varepsilon}}\left[\frac{Q(j)}{Q(i)}\right]^{\frac{\varepsilon-1}{\varepsilon}}
$$

Thus, the consumption of good $j$ as a function of the consumption of good $i$ is given by:

$$
C_{Q A}(j)=\left[\frac{Q(j)}{Q(i)}\right]^{\varepsilon-1} C_{Q A}(i)
$$

Using (A2.7) to substitute for the consumption of each good $j \in(0,1)$ in the budget constraint (A2.1), we obtain:

$$
\int_{0}^{1}\left[\frac{Q(j)}{Q(i)}\right]^{\varepsilon-1} C_{Q A}(i) P^{e} d j=Y_{Q A}
$$

Rearranging the LHS we get:

$$
C_{Q A}(i) Q(i)^{1-\varepsilon} P^{e} \int_{0}^{1} Q(j)^{\varepsilon-1} d j=Y_{Q A}
$$

Dividing by $Q(i)^{1-\varepsilon} P^{e}$ yields the number of units of good $i$ that quantity attentive consumers expect to purchase: 


$$
C_{Q A}(i)=\left[\frac{Q(i)^{\varepsilon-1}}{\int_{0}^{1} Q(j)^{\varepsilon-1} d j}\right] \frac{Y_{Q A}}{P(i)}
$$

However, because the actual price of good $i, P(i)$, might deviate from the expected price $P^{e}$, the actual amount of good $i$ that quantity attentive consumers purchase is given by:

$$
C_{Q A}(i)=\frac{Q(i)^{\varepsilon-1} Y_{Q A}}{P(i) \int_{0}^{1} Q(j)^{\varepsilon-1} d j}
$$

The price index that quantity attentive consumers face is defined by:

$$
C_{Q A} P_{Q A}=\int_{0}^{1} C_{Q A}(i) P(i) d i
$$

where $C_{Q A}$ is the aggregate consumption bundle of quantity attentive consumers. It is

defined by $C_{Q A}=\left\{\int_{0}^{1}\left[C_{Q A}(i) Q(i)\right]^{\frac{\varepsilon-1}{\varepsilon}} d i\right\}^{\frac{\varepsilon}{\varepsilon-1}}$.

We use some good $i \in(0,1)$ as a numeraire and we use equation (A2.7) to substitute for the consumption of every good $j \in(0,1)$ in both sides of (A2.12). Doing so yields

$$
\left\{\int_{0}^{1}\left\{\left[\frac{Q(j)}{Q(i)}\right]^{\varepsilon-1} C_{Q A}(i) Q(j)\right\}^{\frac{\varepsilon-1}{\varepsilon}} d j\right\}^{\frac{\varepsilon}{\varepsilon-1}} P_{Q A}=\int_{0}^{1}\left[\frac{Q(j)}{Q(i)}\right]^{\varepsilon-1} C_{Q A}(i) P(j) d j
$$

Dividing both sides by $C_{Q A}(i)$ and $Q(i)^{1-\varepsilon}$ we get:

$$
P_{Q A}\left[\int_{0}^{1} Q(j)^{\varepsilon-1} d j\right]^{\frac{\varepsilon-1}{\varepsilon}}=\int_{0}^{1} P(j) Q(j)^{\varepsilon-1} d j
$$

Thus, the price level that quantity attentive consumers face is given by: 


$$
P_{Q A}=\frac{\int_{0}^{1} P(j) Q(j)^{\varepsilon-1} d j}{\left[\int_{0}^{1} Q(j)^{\varepsilon-1} d j\right]^{\frac{\varepsilon-1}{\varepsilon}}}
$$

\section{Demand of Price and Quantity Attentive Consumers and the Price Level They}

\section{Face}

Price and quantity attentive consumers choose $C_{P Q A}(i)$ for every $i \in(0,1)$ which maximizes $C_{P Q A}=\left\{\int_{0}^{1}\left[C_{P Q A}(i) Q(i)\right]_{\varepsilon}^{\varepsilon-1} \varepsilon\right\}^{\frac{\varepsilon}{\varepsilon-1}}$, subject to the budget constraint:

$$
\int_{0}^{1} C_{P Q A}(i) P(i) d i=Y_{P Q A}
$$

Denoting the Lagrange multiplier with $\lambda$, the Lagrangian is given by:

$$
\ell=\left\{\int_{0}^{1}\left[\left[C_{P Q A}(i) Q(i)\right]^{\frac{\varepsilon-1}{\varepsilon}} d i\right]\right\}^{\frac{\varepsilon}{\varepsilon-1}}+\lambda \int_{0}^{1}\left[Y_{P Q A}-\left(\tau_{P}+\tau_{Q}\right) W-C_{P Q A}(i) P(i)\right] d i
$$

Differentiating (A3.2) with respect to $C_{P Q A}(i)$ and setting the result equal to zero yields

$$
\left\{\int_{0}^{1}\left[\left[C_{P Q A}(i) Q(i)\right]^{\frac{\varepsilon-1}{\varepsilon}} d i\right]\right\}^{\frac{\varepsilon}{\varepsilon-1}-1}\left[C_{P Q A}(i) Q(i)\right]^{\frac{-1}{\varepsilon}} Q(i)=\lambda P(i)
$$

Differentiating (A3.2) with respect to $C_{P Q A}(j)$ and setting the result equal to zero yields

$$
\left\{\int_{0}^{1}\left[\left[C_{P Q A}(i) Q(i)\right]^{\frac{\varepsilon-1}{\varepsilon}} d i\right]\right\}^{\frac{\varepsilon}{\varepsilon-1}-1}\left[C_{P Q A}(j) Q(j)\right]^{\frac{-1}{\varepsilon}} Q(j)=\lambda P(j)
$$

Dividing (A3.3) by (A3.4) yields: 


$$
\left[\frac{C_{P Q A}(j)}{C_{P Q A}(i)}\right]^{\frac{1}{\varepsilon}}\left[\frac{Q(i)}{Q(j)}\right]^{\frac{\varepsilon-1}{\varepsilon}}=\frac{P(i)}{P(j)}
$$

Rearranging terms, we find that:

$$
C_{P Q A}(j)^{\frac{1}{\varepsilon}}=\frac{P(i)}{P(j)}\left[\frac{Q(j)}{Q(i)}\right]^{\frac{\varepsilon-1}{\varepsilon}} C_{P Q A}(i)^{\frac{1}{\varepsilon}}
$$

Thus, the consumption of good $j$ as a function of the consumption of good $i$ is given by:

$$
C_{P Q A}(j)=\left[\frac{P(i)}{P(j)}\right]^{\varepsilon}\left[\frac{Q(j)}{Q(i)}\right]^{\varepsilon-1} C_{P Q A}(i)
$$

We use equation (A3.7) to substitute for the consumption of every good $j \in(0,1)$ in the budget constraint (A3.1). Doing so yields:

$$
\int_{0}^{1}\left[\frac{P(i)}{P(j)}\right]^{\varepsilon}\left[\frac{Q(j)}{Q(i)}\right]^{\varepsilon-1} C_{P Q A}(i) P(j) d j=Y_{P Q A}
$$

Rearranging the LHS yields:

$$
C_{P Q A}(i) Q(i)^{1-\varepsilon} P(i)^{\varepsilon} \int_{0}^{1}\left[\frac{Q(j)}{P(j)}\right]^{\varepsilon-1} d j=Y_{P Q A}
$$

Thus, the demand function of price and quantity attentive consumers for good $i$ is given by

$$
C_{P Q A}(i)=\frac{\left[\frac{Q(i)}{P(i)}\right]^{\varepsilon-1} Y_{P Q A}}{P(i) \int_{0}^{1}\left[\frac{Q(j)}{P(j)}\right]^{\varepsilon-1} d j}=\frac{\left[\frac{P(i)}{Q(i)}\right]^{1-\varepsilon} Y_{P Q A}}{P(i) \int_{0}^{1}\left[\frac{P(i)}{Q(i)}\right]^{1-\varepsilon} d j}
$$

The price level that price and quantity attentive consumers face is defined by:

$$
C_{P Q A} P_{P Q A}=\int_{0}^{1} C_{P Q A}(i) P(i) d i
$$

where $C_{P Q A}$ is the aggregate consumption bundle of price and quantity attentive

consumers. It is defined by $C_{P Q A}=\left\{\int_{0}^{1}\left[C_{P Q A}(i) Q(i)\right]^{\frac{\varepsilon-1}{\varepsilon}} d i\right\}^{\frac{\varepsilon}{\varepsilon-1}}$. 
We use some good $i \in(0,1)$ as a numeraire and we use (A3.7) to substitute for the consumption of every good $j \in(0,1)$ in both sides of (A3.11). Doing so yields

$$
\begin{aligned}
\left\{\int_{0}^{1}\left\{\left[\left[\frac{P(i)}{P(j)}\right]^{\varepsilon}\left[\frac{Q(j)}{Q(i)}\right]^{\varepsilon-1} C_{P Q A}(i) Q(j)\right]\right\}^{\frac{\varepsilon-1}{\varepsilon}} d j\right\}^{\frac{\varepsilon}{\varepsilon-1}} P_{P Q A}= \\
=\int_{0}^{1}\left[\frac{P(i)}{P(j)}\right]^{\varepsilon}\left[\frac{Q(j)}{Q(i)}\right]^{\varepsilon-1} C_{P Q A}(i) P(j) d j
\end{aligned}
$$

Dividing both sides by $C(i), P(i)^{\varepsilon}$, and $Q(i)^{1-\varepsilon}$, we obtain:

$$
\left\{\int_{0}^{1}\left[\frac{Q(j)}{P(j)}\right]^{\varepsilon-1} d j\right\}^{\frac{\varepsilon}{\varepsilon-1}} P_{P Q A}=\int_{0}^{1}\left[\frac{Q(j)}{P(j)}\right]^{\varepsilon-1} d j
$$

Thus, the price level that price and quantity attentive consumers face is given by:

$$
P_{P Q A}=\left\{\int_{0}^{1}\left[\frac{Q(j)}{P(j)}\right]^{\varepsilon-1} d j\right\}^{\frac{1}{1-\varepsilon}}=\left\{\int_{0}^{1}\left[\frac{P(j)}{Q(j)}\right]^{1-\varepsilon} d j\right\}^{\frac{1}{1-\varepsilon}}
$$

\section{Demand of Inattentive Consumers and the Price Level They Face}

Price and quantity inattentive consumers assume that all goods' prices equal the expected price, $P^{e}$, and that all goods' quantity per package equal the expected quantity per package, $Q^{e}$. They, therefore, maximize $\left\{\int_{0}^{1}\left[C_{I A}(i) Q^{e} d i\right]^{\frac{\varepsilon-1}{\varepsilon}}\right\}^{\frac{\varepsilon}{\varepsilon-1}}$, subject to the budget constraint $\int_{0}^{1} C_{I A}(i) P^{e} d i=Y_{I A}$

Denoting the Lagrange multiplier with $\lambda$, the Lagrangian is given by 


$$
\ell=\left\{\int_{0}^{1}\left[C_{I A}(i) Q^{e}\right]^{\frac{\varepsilon-1}{\varepsilon}} d i\right\}^{\frac{\varepsilon}{\varepsilon-1}}+\lambda \int_{0}^{1}\left[Y_{I A}-C_{I A}(i) P^{e}\right] d i
$$

Differentiating (A4.2) with respect to $C_{I A}(i)$, and setting the result equal to zero yields:

$$
\left\{\int_{0}^{1}\left[C_{I A}(i) Q^{e}\right]^{\frac{\varepsilon-1}{\varepsilon}} d i\right\}^{\frac{\varepsilon}{\varepsilon-1}-1}\left[C_{I A}(i) Q^{e}\right]^{\frac{-1}{\varepsilon}} Q^{e}=\lambda P^{e}
$$

Differentiating (A3.2) with respect to $C_{I A}(j)$ and setting the result equal to zero yields:

$$
\left\{\int_{0}^{1}\left[C_{I A}(i) \omega Q^{e}\right]^{\frac{\varepsilon-1}{\varepsilon}} d i\right\}^{\frac{\varepsilon}{\varepsilon-1}-1}\left[C_{I A}(j) Q^{e}\right]^{\frac{-1}{\varepsilon}} Q^{e}=\lambda P^{e}
$$

Dividing (A3.3) by (A3.4) yields:

$$
\left[\frac{C_{I A}(j)}{C_{I A}(i)}\right]^{\frac{1}{\varepsilon}}=1
$$

Thus, the consumption of good $j$ as a function of the consumption of good $i$ is given by:

$$
C_{I A}(j)=C_{I A}(i)
$$

To find the consumption that price and quantity inattentive consumers expect we use (A4.6) to substitute the consumption of each good $j \in(0,1)$ in the budget constraint (A4.1). Doing so yields:

$$
\int_{0}^{1} C_{I A}(i) P^{e} d j=Y_{I A}
$$

Thus the expected consumption is:

$$
C_{I A}(i)=\frac{Y_{I A}}{P^{e}}
$$

However, because the actual price $P(i)$ can deviate from the expected price $P^{e}$, the actual amount that price and quantity inattentive consumers purchase is given by:

$$
C_{I A}(i)=\frac{Y_{I A}}{P(i)}
$$

The price level that price and quantity inattentive consumers face is defined by: 
$C_{I A} P_{I A}=\int_{0}^{1} C_{I A}(i) P_{I A}(i) d i$

where $C_{I A}$ is the aggregate consumption bundle of price and quantity inattentive

consumers. It is defined by $C_{I A}=\left\{\int_{0}^{1}\left[C_{I A}(i) Q(i)\right]^{\frac{\varepsilon-1}{\varepsilon}} d i\right\}^{\frac{\varepsilon}{\varepsilon-1}}$.

We use some good $i \in(0,1)$ as a numeraire and we use equation (A4.6) to substitute for the consumption of every good $j \in(0,1)$ in both sides of (A4.10). Doing so yields

$$
\left\{\int_{0}^{1}\left[\frac{Y_{I A} Q(i)}{P(i)}\right]^{\frac{\varepsilon-1}{\varepsilon}} d i\right\}^{\frac{\varepsilon}{\varepsilon-1}} P_{I A}=\int_{0}^{1} \frac{Y_{I A}}{P(i)} P(i) d i
$$

Dividing both sides by $Y_{I A}$ we get:

$$
\left\{\int_{0}^{1}\left[\frac{Q(i)}{P(i)}\right]^{\frac{\varepsilon-1}{\varepsilon}} d i\right\}^{\frac{\varepsilon}{\varepsilon-1}} P_{I A}=1
$$

Thus, the price level that price and quantity inattentive consumers face is given by:

$$
P_{I A}=\left\{\int_{0}^{1}\left[\frac{Q(i)}{P(i)}\right]^{\frac{\varepsilon-1}{\varepsilon}} d i\right\}^{\frac{\varepsilon}{1-\varepsilon}}=\left\{\int_{0}^{1}\left[\frac{P(i)}{Q(i)}\right]^{\frac{\varepsilon}{\varepsilon-1}} d i\right\}^{\frac{\varepsilon}{1-\varepsilon}}
$$




\section{References}

Ameriks, J., A. Caplin, and J. Leahy (2004), “The Absent-Minded Consumers,” NBER Working Paper, No. 10216.

Armstrong, M. and Y. Chen (2009), "Inattentive Consumers and Product Quality," Journal of the European Economic Association 7, 411-422.

Bagwell, L.S. and D.B. Bernheim (1996), "Veblen Effects in a Theory of Conspicuous Consumption,” American Economic Review 66, 349-373.

Ball, L., N.G. Mankiw, and R. Reis (2005), "Monetary Policy for Inattentive Economies,” Journal of Monetary Economics 52, 703-725.

Bils, M. and P.J. Klenow (2004), “Some Evidence on the Importance of Sticky Prices," Journal of Political Economy 112 , 947-985.

Blanchard, O. and S. Fischer (1989), Lectures on Macroeconomics (Cambrdige, MA: MIT Press)

Blinder, A.S., E.D. Canetti, D.E. Lebow and J.B. Rudd (1998), Asking about Prices: A New Approach to Understanding Price Stickiness (New York, NY: Russell Sage Foundation).

Carlton, D.W. (1989), “The Theory and the Facts of How Markets Clear: Is Industrial Organization Valuable for Understanding Macroeconomics?" in Handbook of Industrial Organization, Vol. 1, R. Schmalensee and R. Willig (Eds.), (Maryland Heights, MO: Elsevier), 909-946.

Carlton, D.W. (1991), “The Theory of Allocation and Its Implications for Marketing and Industrial Structure: Why Rationing is Efficient," Journal of Law and Economics 34, 231-262.

Chen, H., D. Levy, S. Ray and M. Bergen (2008), “Asymmetric Price Adjustment in the Small,” Journal of Monetary Economics 55, 728-737.

Chevalier, J. A., A.K. Kashyap, and P.E. Rossi (2003), "Why Don’t Prices Rise in Periods of Peak Demand? Evidence from Scanner Data,” American Economic Review 93, 15-37.

Dehn, M.J. (2008), Working Memory and Academic Learning: Assessment and Intervention (Bognor Regis, UK: John Wiley and Sons).

Dickson, P.R. and A.G. Sawyer (1990), “The Price Knowledge and Search of Supermarket Shoppers,” Journal of Marketing 54, 42-53.

Dotsey, M., R.G. King and A.L. Wolman (1999), "State-Dependent Pricing and the General Equilibrium Dynamics of Money and Output,” Quarterly Journal of Economics 114, 655-690.

Falkinger, J. (2008), "Limited Attention as a Scarce Resource in Information-Rich Economies,” Economic Journal 118, 1596-1620.

Fox, E. J. and S.J. Hoch (2005), “Cherry Pickers,” Journal of Marketing 69, 46-62.

Gabaix, X. and D. Laibson (2006), "Shrouded Attributes, Consumer Myopia, and Information Suppression in Competitive Markets,” Quarterly Journal of Economics 121, 505-540.

Gabaix, X., D. Laibson, G. Molocho and S. Weinberg (2006), "Costly Information Acquisition: Experimental Analysis of Bounded Rational Model,” American Economic Review 96, 1043-1068.

Gabor, A. and C.W.J. Granger (1961), "On the Price Consciousness of Consumers,” Applied Statistics 10, 170-188.

Gabor, A. and C.W.J. Granger (1966), "Price as an Indicator of Quality; Report on an Enquiry,” Economica 33, 43-70. 
Gagnon, E. (2009), "Price Setting During Low and High Inflation: Evidence from Mexico,” Quarterly Journal of Economics 124, 1221-1263.

Galí, J. (2008), Monetary Policy, Inflation, and the Business Cycle: An Introduction to the New Keynesian Framework (Princeton, NJ: Princeton University Press).

Gourville, J.T. and J.J. Koehler (2004), Downsizing Price Increases: A Greater

Sensitivity to Price than Quantity in Consumer Markets,” Research Paper No. 0401, Harvard Business School.

Gupta, S. and P. Chintagunta (1994), “On Using Demographic Variables to Determine Segment Membership in Logit Mixture Models,” Journal of Marketing Research 31, 128-136.

Hoch, S.J., B.D. Kim, A.L. Montgomery, and P.E. Rossi (1995), “Determinants of Store-

Level Price Elasticity,” Journal of Marketing Research 32, 17-29.

Kahneman, D. and S. Frederick (2002), "Representativeness Revisited: Attribute

Substitution in Intuitive Judgment," in Heuristics and Biases: The Psychology of

Intuitive Judgment, T. Gilovich, D. Griffin and D. Kahneman (eds.), (New York,

NY: Cambridge University Press), 49-81.

Kahneman, D. and A. Treisman (1984), "Changing Views of Attention and

Automaticity,” in R. Parasuraman, D. Davies and J. Beatty (Eds.), Variants of

Attention (New York, NY: Academic Press).

Kalyanaram, G. and R.S. Winer (1995), "Empirical Generalizations from Reference Price

Research,” Marketing Science 14, G161-G169.

Klenow, P. and J. Willis (2007), “Sticky Information and Sticky Prices,” Journal of

Monetary Economics 54 (Supplement 1), 79-99.

Knotek, E.S. II (2010), “A Tale of Two Rigidities: Sticky Prices in a Sticky-Information Environment,” Journal of Money, Credit and Banking 42, 1543-1564.

Knotek, E.S. II (2011), “Convenient Prices and Price Rigidity: Cross-Section Evidence,” Review of Economics and Statistics, forthcoming.

Konieczny, J. (1993), “Variable Price Adjustment Costs,” Economic Inquiry 31, 488-98.

Krieder, R.E. and S. Han (2004), "Promotion Thresholds: Price Change Insensitivity or

Risk Hurdle?" Canadian Journal of Administrative Sciences 21, 255-271.

Laibson, D. (2001), “A Cue Theory of Consumption,” Quarterly Journal of

Economics 116, 81-119.

Levy, D., H. Chen, G. Müller, S. Dutta and M. Bergen (2010), "Holiday Price Rigidity and Cost of Price Adjustment,” Economica 77, 172-198.

Levy, D., D. Lee, H. Chen, R. Kauffman, and M. Bergen (2011), "Price Points and Price Rigidity,” Review of Economics and Statistics, forthcoming.

Levy, D. and A. Young (2004), "The Real Thing: Nominal Price Rigidity of the Nickel Coke, 1886-1959,” Journal of Money, Credit and Banking 36, 765-799.

Mankiw, N.G. and R Reis (2002), "Sticky Decisions versus Sticky Prices: A Proposal to Replace the New Keynesian Phillips Curve” Quarterly Journal of Economics 117, 1295-1328.

Mankiw, N.G. and R. Reis (2007), “Sticky Information in General Equilibrium,” Journal of the European Economic Association 2, 603-613.

Mankiw, N.G. and R. Reis (2010), "Imperfect Information and Aggregate Supply,” NBER Working Paper, No. 15773.

Mazumdar, T. and P. Papatla (2000), “An Investigation of Reference Price Segments,” Journal of Marketing Research 37, 246-258.

Miyazaki, D.A., D.E. Sprott and K.C. Manning (2000), "Unit Prices on Retail Shelf Labels: An Assessment of Information Prominence,” Journal of Retailing 76, 93112. 
Monroe, K.B. and A.Y. Lee (1999), “Remembering Versus Knowing: Issues in Buyers’

Processing of Price Information,” Academy of Marketing Science 27, 207-225.

Mortimer, G.S. (2009), “Profiling the Male Grocery Shopper,” Ph.D. Thesis, Griffith

Business School, Griffith University.

Nakamura, E. and J. Steinsson (2008), "Five Facts About Prices: A Reevaluation of

Menu Cost Models,” Quarterly Journal of Economics 123, 1415-1464.

Navon, D. and D. Gopher (1979), "On the Economy of the Human Processing System,” Psychological Review 86, 215-255.

Raajpoot, N.A., A. Sharma, and J.C. Chebat (2008), “The Role of Gender and Work

Status in Shopping Center Patronage,” Journal of Business Research 61, 825-833.

Reis, R. (2006a), “Inattentive Consumers,” Journal of Monetary Economics 53, 17611800.

Reis, R. (2006b), “Inattentive Producers,” Review of Economic Studies 73, 793-821.

Reis, R. (2009), "Optimal Monetary Policy Rules in an Estimated Sticky-Information Model,” American Economic Journal: Macroeconomics 1, 1-28.

Rotemberg, J.J. (1983), “Sticky Prices in the United States,” Journal of Political Economy 90, 1187-1211.

Rotemberg, J.J. (2005), "Customer Anger at Price Increases, Changes in the Frequency of Price Adjustment and Monetary Policy,” Journal of Monetary Economics 52, 829_ 852.

Sims, C. (2003), “Implication of Rational Inattention,” Journal of Monetary Economics 50, 665-690.

Smith, E.E., S. Nolen-Hoeksema, B.L. Fredrickson and G.L. Loftus (2003), Atkinson and Hilgard's Introduction to Psychology, $14^{\text {th }}$ Edition (Belmont, CA:

Wadswoth/Thomson Learning).

Swan, P.L. (1970), "Market Structure and Technological Progress: The Influence of Monopoly on Product Innovation,” Quarterly Journal of Economics 84, 627-638.

Thaler, R.H. (2000), “From Homo Economicus to Homo Sapiens,” Journal of Economic Perspectives 14, 133-141.

Treisman, A. (1993), “The Perception of Features and Objects,” in A. Baddeley and L. Weiskrantz (Eds.), Attention: Selection, Awareness and Control - a Tribute to Donald Broadbent (Oxford: Clarendon Press University), 5-35.

Vanhuele, M. and X. Drèze (2002), "Measuring the Price Knowledge Shoppers Bring to the Store," Journal of Marketing 66, 72-85.

Warner, E.J. and R.B. Barsky (1995), “The Timing and Magnitude of Retail Store Markdowns: Evidence from Weekends and Holidays,” Quarterly Journal of Economics 110, 321-352. 
Table 1. Descriptive Statistics of the Supermarkets Surveyed

\begin{tabular}{|l|l|l|l|l|l|}
\hline Supermarket & City & $\begin{array}{l}\text { Supermarket } \\
\text { Chain }\end{array}$ & Discount & $\begin{array}{l}\text { Type of } \\
\text { Location }\end{array}$ & Location \\
\hline 1 & Petah-Tiquah & Shufersal & Yes & Shopping Zone & Outside \\
\hline 2 & Rehovot & Blue Center & No & Street & Suburb \\
\hline 3 & Givat Shemuel & Blue Center & No & Shopping Center & City Center \\
\hline 4 & Petah-Tiquah & Private & Yes & Shopping Zone & Outside \\
\hline 5 & Bnei Beraq & Blue Center & Yes & Street & City Center \\
\hline 6 Alef & Petah-Tiquah & Shufersal & Yes & Shopping Zone & Outside \\
\hline 7 Yad Yitzhak & Petah-Tiquah & Private & Yes & Shopping Zone & Outside \\
\hline 8 & Ramat-Gan & Shufersal & No & Shopping Center & City Center \\
\hline 9 & Ramat-Gan & Blue Center & No & Shopping Center & Suburb \\
\hline 10 & Netanya & Shufersal & Yes & Shopping Zone & Outside \\
\hline 11 & Petah-Tiquah & Shufersal & Yes & Shopping Zone & Outside \\
\hline 12 & Netanya & Shufersal & Yes & Shopping Zone & Outside \\
\hline 13 & Tel-Aviv & Shufersal & Yes & Shopping Zone & City Center \\
\hline 14 & Bat-Yam & Private & Yes & Shopping-Zone & City-Center \\
\hline 15 & Private & Yes & Shopping-Zone & Suburb \\
\hline
\end{tabular}

\section{Notes:}

There are two large supermarket chains, Shufersal and Blue Center.

Discount column indicates whether or not the supermarket is promoted as a low-price supermarket. 
Table 2. Socio-Economic Status of Consumers by Cities Where the Supermarkets Are Located

\begin{tabular}{|l|c|c|c|c|c|c|c|c|}
\hline City & $\begin{array}{l}\text { Income } \\
\text { in NIS }\end{array}$ & Unemployment & Computer & Cars & Household & Academics & Immigrants & $\begin{array}{l}\text { Economic- } \\
\text { Status }\end{array}$ \\
\hline Petah-Tiquah & 6,386 & $7.6 \%$ & $63 \%$ & $59 \%$ & 3.2 & $15 \%$ & $29.3 \%$ & 7 \\
\hline Rehovot & 6,952 & $8.2 \%$ & $67 \%$ & $74 \%$ & 3.3 & $15 \%$ & $20.8 \%$ & 7 \\
\hline $\begin{array}{l}\text { Givat } \\
\text { Shemuel }\end{array}$ & 7,412 & $7.8 \%$ & $52 \%$ & $60 \%$ & 2.5 & $18 \%$ & $10.2 \%$ & 8 \\
\hline Bnei Beraq & 4,735 & $10.6 \%$ & $38 \%$ & $18 \%$ & 4.0 & $8 \%$ & $6.9 \%$ & 2 \\
\hline Netanya & 5,339 & $12.9 \%$ & $41 \%$ & $54 \%$ & 3.0 & $13 \%$ & $26.6 \%$ & 5 \\
\hline Bat-Yam & 4,807 & $11.6 \%$ & $37 \%$ & $36 \%$ & 2.8 & $11 \%$ & $32.1 \%$ & 6 \\
\hline Tel Aviv & 7,214 & $10.0 \%$ & $57 \%$ & $46 \%$ & 2.3 & $20 \%$ & $12.2 \%$ & 8 \\
\hline
\end{tabular}

Notes:

Income $=$ the average wage of an employed person in 2001 in NIS (The exchange rate was NIS4.21/US\$1). Unemployment $=$ unemployment rate in 2002. Computer $=$ the share of households that owned at least one computer in 2002. Cars $=$ the share of households with at least one car in 2002. Household $=$ the size of the average household in 2002. Academics $=$ the share of population with BA or higher degree in 1995. Immigrants = the share of population in 2002 that immigrated to Israel after 1989. Economic Status = Israel Central Bureau of Statistics index ranking cities on a scale of 1-10, where 1 indicates the lowest socio-economic status and 10 indicates the highest socio-economic status. Source: Israel Central Bureau of statistics (2002), and Israel Central Bureau of Statistics Socio-Economic Index for Cities, 1995,

www.cbs.gov.il/mifkad/tables/pirsom13/13.xls. 
Table 3. Summary Statistics of the Surveyed Consumers by Supermarket

\begin{tabular}{|c|c|c|c|c|c|c|c|c|c|}
\hline Supermarket & Women & Age Group & Academics & $\begin{array}{l}\text { Family } \\
\text { Size }\end{array}$ & \#Cars & Religious & $\begin{array}{c}\text { Expenditures } \\
\text { in NIS }\end{array}$ & \#Goods & \#Observations \\
\hline 1 & $56 \%$ & $\begin{array}{l}18-24 \\
(24 \%)\end{array}$ & $35 \%$ & $\begin{array}{c}3.56 \\
(1.24)\end{array}$ & $\begin{array}{c}1.5 \\
(0.86) \\
\end{array}$ & $10 \%$ & $\begin{array}{c}270 \\
(101.4)\end{array}$ & 8.0 & 46 \\
\hline 2 & $59 \%$ & $\begin{array}{l}46-55 \\
(29 \%)\end{array}$ & $58 \%$ & 4.20 & $\begin{array}{c}1.8 \\
(0.82)\end{array}$ & $16.6 \%$ & $\begin{array}{c}359 \\
(76.8)\end{array}$ & 5.6 & 208 \\
\hline 3 & $70 \%$ & $\begin{array}{l}25-34 \\
(34 \%) \\
\end{array}$ & $56 \%$ & $\begin{array}{c}3.38 \\
(1.59) \\
\end{array}$ & $\begin{array}{c}2.3 \\
(0.68) \\
\end{array}$ & $14.5 \%$ & $\begin{array}{c}226 \\
(171) \\
\end{array}$ & 2.4 & 152 \\
\hline 4 & $57 \%$ & $\begin{array}{l}35-45 \\
(33 \%)\end{array}$ & $61 \%$ & $\begin{array}{c}3.71 \\
(1.36) \\
\end{array}$ & $\begin{array}{c}2.63 \\
(0.69) \\
\end{array}$ & $13.0 \%$ & $\begin{array}{c}468.5 \\
(151.53)\end{array}$ & 5.2 & 100 \\
\hline 5 & $70 \%$ & $\begin{array}{l}46-55 \\
(46 \%) \\
\end{array}$ & $56 \%$ & $\begin{array}{c}5.24 \\
(1.16) \\
\end{array}$ & $\begin{array}{c}1.9 \\
(0.8) \\
\end{array}$ & $100 \%$ & $\begin{array}{c}353.65 \\
(176.91) \\
\end{array}$ & 3.1 & 41 \\
\hline 6 & $44 \%$ & $\begin{array}{l}35-45 \\
(39 \%) \\
\end{array}$ & $53 \%$ & $\begin{array}{c}3.90 \\
(1.49) \\
\end{array}$ & $\begin{array}{c}2.44 \\
(0.85) \\
\end{array}$ & $25.4 \%$ & $\begin{array}{c}131.58 \\
(102.67)\end{array}$ & 5.1 & 114 \\
\hline 7 & $49 \%$ & $\begin{array}{l}46-55 \\
(30 \%) \\
\end{array}$ & $50 \%$ & $\begin{array}{c}4.30 \\
(1.43) \\
\end{array}$ & $\begin{array}{c}2.71 \\
(0.96) \\
\end{array}$ & $48.6 \%$ & $\begin{array}{c}221.43 \\
(144.68) \\
\end{array}$ & 4.6 & 70 \\
\hline 8 & $71 \%$ & $\begin{array}{l}25-34 \\
(32 \%) \\
\end{array}$ & $56 \%$ & $\begin{array}{c}3.63 \\
(1.61)\end{array}$ & $\begin{array}{c}2.1 \\
(0.74) \\
\end{array}$ & $43.9 \%$ & $\begin{array}{c}321.95 \\
(153.32)\end{array}$ & 4.4 & 41 \\
\hline $9^{30}$ & $49 \%$ & $\begin{array}{c}\text { Under } 24 \\
(31 \%)\end{array}$ & $85 \%$ & $\begin{array}{c}3.87 \\
(1.67)\end{array}$ & $\begin{array}{c}2.16 \\
(0.86) \\
\end{array}$ & $52.4 \%$ & $\begin{array}{c}197.83 \\
(110.27) \\
\end{array}$ & 2.5 & 61 \\
\hline 10 & $71 \%$ & $\begin{array}{l}25-34 \\
(34 \%)\end{array}$ & $56 \%$ & $\begin{array}{c}3.53 \\
(1.40)\end{array}$ & $\begin{array}{c}1.12 \\
(0.81)\end{array}$ & $50.0 \%$ & $\begin{array}{c}264.5 \\
(145.87)\end{array}$ & 4.7 & 100 \\
\hline 11 & $57 \%$ & $\begin{array}{l}25-34 \\
(55 \%) \\
\end{array}$ & $70 \%$ & $\begin{array}{c}3.54 \\
(1.29) \\
\end{array}$ & $\begin{array}{c}2.34 \\
(0.69) \\
\end{array}$ & $65.6 \%$ & $\begin{array}{c}400.0 \\
(157.78)\end{array}$ & 3.6 & 99 \\
\hline 12 & $57 \%$ & $\begin{array}{l}35-45 \\
(34 \%) \\
\end{array}$ & $53 \%$ & $\begin{array}{c}4.17 \\
(1.46) \\
\end{array}$ & $\begin{array}{c}2.38 \\
(0.70) \\
\end{array}$ & $44.54 \%$ & $\begin{array}{c}475.91 \\
(159.66) \\
\end{array}$ & 2.3 & 110 \\
\hline 13 & $58 \%$ & $\begin{array}{l}46-55 \\
(37 \%)\end{array}$ & $47 \%$ & $\begin{array}{c}3.32 \\
(1.49)\end{array}$ & $\begin{array}{c}2.21 \\
(0.80)\end{array}$ & $15.71 \%$ & $\begin{array}{c}409.29 \\
(178.82)\end{array}$ & 4.1 & 70 \\
\hline 14 & $66 \%$ & $\begin{array}{l}36-45 \\
(28 \%) \\
\end{array}$ & $27 \%$ & $\begin{array}{c}3.51 \\
(1.33) \\
\end{array}$ & $\begin{array}{c}1.5 \\
(0.93) \\
\end{array}$ & $15 \%$ & $\begin{array}{c}386.67 \\
(153.17) \\
\end{array}$ & 3.75 & 60 \\
\hline 15 & $65 \%$ & $\begin{array}{l}46-55 \\
(28 \%) \\
\end{array}$ & $32 \%$ & $\begin{array}{c}3.1 \\
(1.26) \\
\end{array}$ & $\begin{array}{c}1.84 \\
(1.33) \\
\end{array}$ & $7 \%$ & $\begin{array}{c}274.16 \\
(151,12)\end{array}$ & 8.1 & 60 \\
\hline
\end{tabular}

Notes:

Supermarket $=$ code of the supermarket (Table 1 ). Women $=\%$ of women. Age Group $=$ the most common age group, in parentheses: the percentage of that group in the city population. Academics $=\%$ with a BA or higher degree. Family Size $=$ the average family size with the standard deviation. \#Cars = the average number of cars with the standard deviation. Religious = \% of religious or very religious (orthodox Jews). Expenditure = average amount spent during a shopping trip with the standard deviation. \#Goods = average number of sampled goods purchased. \#Observations = number of consumers surveyed. The exchange rate during the period was NIS 4.37/US\$1.

\footnotetext{
${ }^{30}$ This supermarket is located on a university campus and thus most shoppers there are students who usually buy only few items.
} 
Table 4. Product Categories Included In the First Survey

\begin{tabular}{|c|c|c|}
\hline Category & \#Brands & $P>$ NIS 20 \\
\hline Turkish Coffee & 4 & No \\
\hline Instant Coffee & 6 & Yes \\
\hline Bamba Peanut Snack & 4 & No \\
\hline Lemon/Lime Soft Drink (6-Pack) & 2 & Yes \\
\hline Mineral Water (6-Pack) & 5 & No \\
\hline Coca Cola (6-Pack) & 5 & Yes \\
\hline Orange Juice & 6 & No \\
\hline Chocolate Spread & 5 & No \\
\hline Soft Cheese & 8 & No \\
\hline Yoghurt (8-pack) & 4 & No \\
\hline Beer (6-pack) & 2 & Yes \\
\hline Ice Cream & 3 & Yes \\
\hline Sugar & 2 & No \\
\hline Thick and Creamy Snack & 2 & No \\
\hline Pasta and Rice & 4 & No \\
\hline Dish Soap & 5 & No \\
\hline Cleaning Detergent & 4 & No \\
\hline Humus and Tahina salad & 4 & No \\
\hline Ready Made Cake & 4 & No \\
\hline Processed Meat & 5 & No \\
\hline Shampoo & 2 & No \\
\hline Pickled Cucumbers & 2 & No \\
\hline BBQ Equipment & 4 & Yes \\
\hline Basic Food & 7 & No \\
\hline Tomato Concentrate & 2 & No \\
\hline Fruits & 1 & No \\
\hline Sweet Red Wine & 2 & No \\
\hline Toilet Paper & 2 & No \\
\hline Waffles & 2 & No \\
\hline Crackers & 4 & No \\
\hline Butter and Margarine & 2 & No \\
\hline Clothing & 2 & No \\
\hline Snack Cup Noodles & 2 & No \\
\hline Ketchup & 3 & No \\
\hline Ice Cream Snacks & 2 & Yes \\
\hline Eggplant Salad & 3 & No \\
\hline Cabbage Salad & 4 & No \\
\hline Total & 130 & \\
\hline
\end{tabular}

Notes:

\#Brand $=$ number of brands in the category. $P>$ NIS $20=$ Is the average price in the category higher than NIS 20 or not?. 
Table 5. Summary Statistics for Product Categories in Supermarket 3

\begin{tabular}{|l|l|l|l|l|l|l|l|l|}
\hline Category & Max Price & Min Price & $\begin{array}{l}\text { Average } \\
\text { Price }\end{array}$ & $\begin{array}{l}\text { Average } \\
\text { Quantity }\end{array}$ & $\begin{array}{l}\text { Price } \\
\text { Changes }\end{array}$ & $\begin{array}{l}\text { Share of } \\
\text { Consumers }\end{array}$ & frequency & Brands \\
\hline Coca-Cola & 6.29 & 4.42 & 5.04 & 1.63 liters & 0.11 & $30 \%$ & 0.30 & 4 \\
\hline Diet Coca-Cola & 6.29 & 4.49 & 5.27 & 1.5 liters & 0.05 & $20 \%$ & 0.20 & 3 \\
\hline Mineral Water, 6-pack & 15.99 & 10.00 & 14.19 & 9.75 liters & 0.06 & $25 \%$ & 0.25 & 4 \\
\hline Black Coffee & 8.00 & 3.66 & 6.20 & $0.218 \mathrm{~kg}$ & 0.015 & $16 \%$ & 0.16 & 8 \\
\hline Chocolate Waffles & 5.40 & 1.30 & 12.83 & $0.325 \mathrm{~kg}$ & 0.006 & $4 \%$ & 0.04 & 6 \\
\hline Bamba Peanut Snack & 4.49 & 2.99 & 3.94 & $0.08 \mathrm{~kg}$ & 0 & $32 \%$ & 0.32 & 7 \\
\hline Chocolate Spread & 17.84 & 10.99 & 11.62 & $0.475 \mathrm{~kg}$ & 0.016 & $9 \%$ & 0.09 & 4 \\
\hline Dairy Chocolate & 10.99 & 5.49 & 10.34 & $0.098 \mathrm{~kg}$ & 0 & $9 \%$ & 0.09 & 8 \\
\hline Canned Tuna & 5.99 & 4.25 & 5.06 & $0.148 \mathrm{~kg}$ & 0.049 & $12 \%$ & 0.12 & 7 \\
\hline Tomato Concentrate & 9.23 & 5.99 & 5.06 & $0.38 \mathrm{~kg}$ & 0.036 & $9 \%$ & 0.09 & 3 \\
\hline Canned Corn & 10.98 & 5.49 & 7.00 & $0.44 \mathrm{~kg}$ & 0.0779 & $4 \%$ & 0.04 & 5 \\
\hline Sugar & 9.49 & 3.99 & 5.06 & $1.00 \mathrm{~kg}$ & 0.03 & $4 \%$ & 0.04 & 4 \\
\hline Eggs, medium size & 20.99 & 9.40 & 15.92 & 12 & 0.068 & $17 \%$ & 0.17 & 3 \\
\hline Cottage Cheese & 5.79 & 4.82 & 12.14 & $0.25 \mathrm{~kg}$ & 0.064 & $37.5 \%$ & 0.375 & 3 \\
\hline Diapers & 71.99 & 39.98 & 57.38 & 54.18 & 0.018 & $4 \%$ & 0.04 & 4 \\
\hline Fabric Softener & 26.99 & 19.99 & 23.73 & 4 liters & 0.052 & $7 \%$ & 0.07 & 6 \\
\hline Plastic Cups & 4.49 & 4.49 & 4.49 & 100 & 0 & $16 \%$ & 0.16 & 1 \\
\hline
\end{tabular}

Notes:

The prices in each category are reported for the categories' standard units, which are: 1.5 liters for the Coca-Cola, Diet Coca-Cola and mineral water categories; $100 \mathrm{~g}$ for black coffee, chocolate waffles, dairy chocolate, canned tuna, tomato concentrate and canned corn categories; 8g for Bamba peanut snacks; 500g for chocolate spread; 250g for cottage cheese; $1 \mathrm{~kg}$ for sugar; 4 liters for fabric softener, 12 eggs, 50 diapers and 100 plastic cups. The Average Quantity indicates the average package size/content in a category. In categories where packages contain more than one unit the average quantity reported is the number of unites per package(e.g., in the mineral waters category, each pack contains 6 bottles). The price changes column indicates the average number of price changes per week per category over the 11weeks period. The Brands column indicates the number of brands sold in each category. 
Table 6. Consumers' Knowledge of Goods’ Prices and Quantities

\begin{tabular}{|c|c|c|}
\hline \multirow[b]{2}{*}{ Variable } & \multicolumn{2}{|c|}{ Dependent Variable } \\
\hline & Percentage Price Recall Error & Percentage Quantity Recall Error \\
\hline Religion & $\begin{array}{l}-0.031 \\
(0.082)\end{array}$ & $\begin{array}{l}1.04 * \\
(0.625)\end{array}$ \\
\hline Academic & $\begin{array}{l}-0.015 \\
(0.073)\end{array}$ & $\begin{array}{c}-1.83 * * * \\
(0.551)\end{array}$ \\
\hline Gender & $\begin{array}{l}0.119^{*} \\
(0.071)\end{array}$ & $\begin{array}{l}0.889 * \\
(0.537)\end{array}$ \\
\hline Large Family & $\begin{array}{l}-0.075 \\
(0.102)\end{array}$ & $\begin{array}{l}-0.951 \\
(0.773)\end{array}$ \\
\hline Discount Supermarket & $\begin{array}{c}0.051 \\
(0.291)\end{array}$ & $\begin{array}{l}-3.86^{*} \\
(2.21)\end{array}$ \\
\hline Outside City & $\begin{array}{c}0.19 \\
(0.28)\end{array}$ & $\begin{array}{c}2.52 \\
(2.12)\end{array}$ \\
\hline Multi-Unit Pack & $\begin{array}{c}-1.09 * * * \\
(0.123) \\
\end{array}$ & $\begin{array}{r}2.86^{* * *} \\
(0.936) \\
\end{array}$ \\
\hline $\begin{array}{l}\text { Goods Consumed within a Short } \\
\text { Period }\end{array}$ & $\begin{array}{c}0.008 \\
(0.125) \\
\end{array}$ & $\begin{array}{c}-2.55^{* * *} \\
(0.949) \\
\end{array}$ \\
\hline Recalled Price & $\begin{array}{c}0.081^{* * *} \\
(0.002)\end{array}$ & $\begin{array}{c}-0.028 * * \\
(0.014)\end{array}$ \\
\hline Average Category Price & $\begin{array}{c}-0.024 * * * \\
(0.009)\end{array}$ & $\begin{array}{c}0.055 \\
(0.068) \\
\end{array}$ \\
\hline Recalled Quantity & $\begin{array}{l}-0.0002 \\
(0.0008)\end{array}$ & $\begin{array}{c}0.079 * * * \\
(0.007)\end{array}$ \\
\hline Average Category Quantity & $\begin{array}{l}-0.0003 \\
(0.0013)\end{array}$ & $\begin{array}{c}-0.145^{* * *} \\
(0.01)\end{array}$ \\
\hline Category Price $S D$ & $\begin{array}{c}-0.036 * * * \\
(0.009)\end{array}$ & $\begin{array}{l}-0.009 \\
(0.07) \\
\end{array}$ \\
\hline Category Quantity SD & $\begin{array}{l}-0.0004 \\
(0.0007) \\
\end{array}$ & $\begin{array}{c}0.0209^{* *} \\
(0.013)\end{array}$ \\
\hline Year 2008 & $\begin{array}{l}-0.224^{*} \\
(0.144)\end{array}$ & $\begin{array}{c}-6.75^{* * * *} \\
(1.11) \\
\end{array}$ \\
\hline Holiday & $\begin{array}{l}-0.158^{*} \\
(0.096)\end{array}$ & $\begin{array}{c}-1.62 * * \\
(0.74)\end{array}$ \\
\hline Constant & $\begin{array}{c}0.248 \\
(0.254) \\
\end{array}$ & $\begin{array}{l}4.5^{* *} \\
(1.93)\end{array}$ \\
\hline Number of Observations & 4184 & 4184 \\
\hline$\chi^{2}$ & $2071.7^{* * *}$ & $1349.8^{* * *}$ \\
\hline
\end{tabular}

Notes:

We used the SUR method. The dependent variables are the absolute values of the percentage price recall error and quantity recall error. Standard errors are reported in parenthesis.

*- Significant at $10 \%$. **- Significant at 5\%.**-Significant at $1 \%$. 
Table 7. Probability of a Correct Recall, Conditional on Consumers’ Attention Mode

\begin{tabular}{|c|c|c|c|}
\hline \multicolumn{2}{|c|}{ Consumers' attributes } & \multicolumn{2}{|c|}{ Goods' Attributes } \\
\hline Religion & $\begin{array}{c}-0.257 * \\
(0.17)\end{array}$ & Small Discount & $\begin{array}{c}-1.153 * * * \\
(0.285)\end{array}$ \\
\hline Academic & $\begin{array}{l}0.111 \\
(0.12)\end{array}$ & Supermarket-2 Dummy & $\begin{array}{c}-0.935^{* * *} \\
(0.229)\end{array}$ \\
\hline Gender & $\begin{array}{c}-0.08 \\
(0.119)\end{array}$ & Holiday $\times$ Expensive 20 & $\begin{array}{c}2.06 * * * \\
(0.422)\end{array}$ \\
\hline Large Family & $\begin{array}{c}0.659 * * * \\
(0.21)\end{array}$ & Price Discount & $\begin{array}{c}1.789 * * * \\
(0.24)\end{array}$ \\
\hline Middle Age & $\begin{array}{c}0.486 * * * \\
(0.146)\end{array}$ & Quantity Discount & $\begin{array}{c}1.315^{* * *} \\
(0.217)\end{array}$ \\
\hline Cashier-Parking & $\begin{array}{c}-0.271^{* *} \\
(0.123)\end{array}$ & Holiday $\times$ Price Discount & $\begin{array}{l}-0.325 \\
(0.365)\end{array}$ \\
\hline Holiday & $\begin{array}{c}0.868 * * * \\
(0.154)\end{array}$ & Holiday $\times$ Quantity Discount & $\begin{array}{c}1.02 * * * \\
(0.3)\end{array}$ \\
\hline Constant & $\begin{array}{c}0.569 * * * \\
(0.125)\end{array}$ & Constant & $\begin{array}{c}0.871 \\
(0.639)\end{array}$ \\
\hline Number of Obser & & 1443 & \\
\hline Log Likelihood & & -1597.94 & \\
\hline$\chi^{2}$ & & $57.85^{* * *}$ & \\
\hline
\end{tabular}

Notes:

Consumers' Attributes = attributes which affect the probability that consumers are attentive. Goods' Attributes $=$ attributes which affect the probability that consumers correctly recall whether or not a given good is offered at a discount. The dependent variable is Correct Recall. Robust standard errors are reported in parenthesis.

*- Significant at $10 \%$.**- Significant at 5\%.***- Significant at $1 \%$. 
Figure 1. Baseline parameters

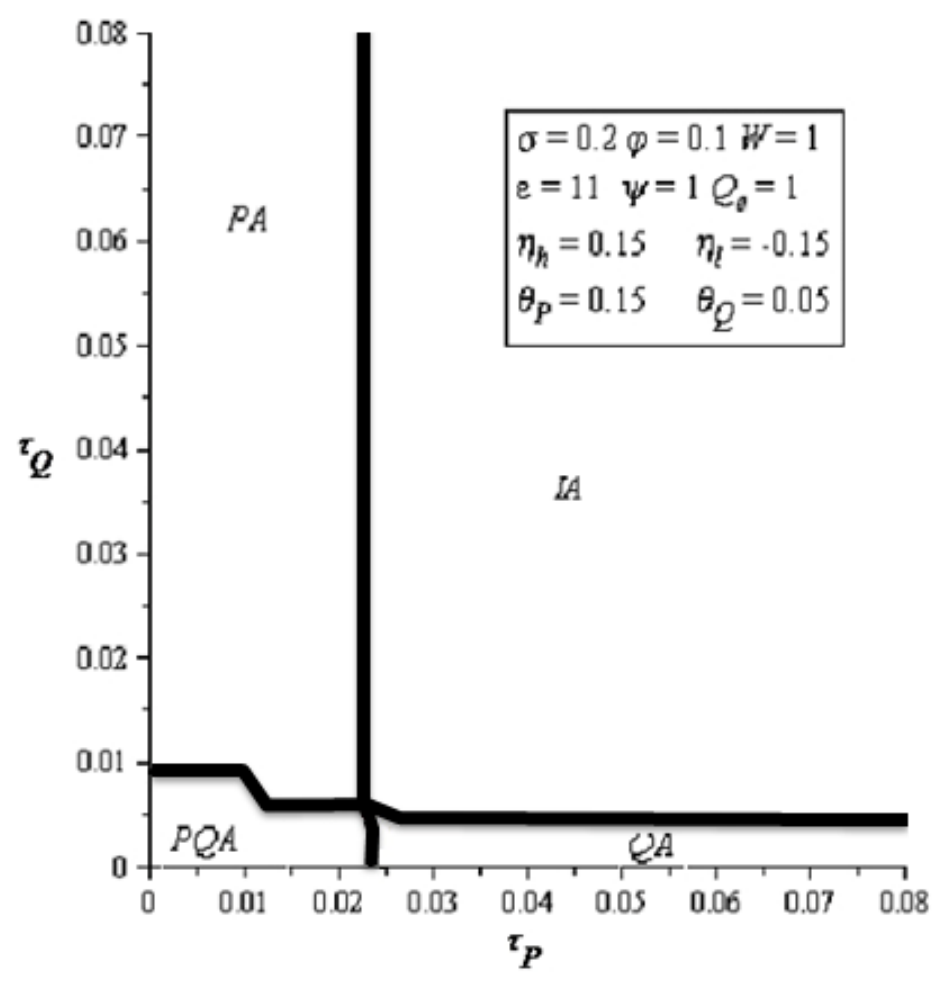

Figure 2. The effect of decreasing the absolute value of the elasticity of marginal utility with respect to consumption, $\sigma$, from 0.2 to 0.05

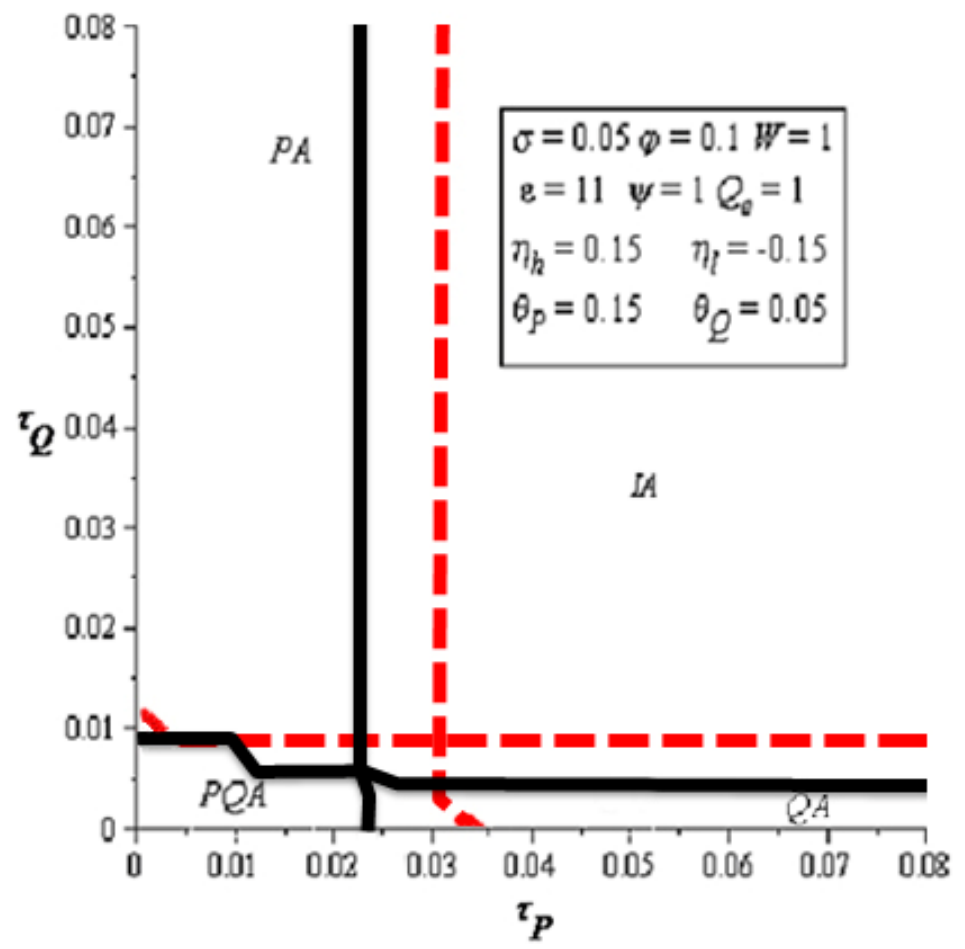

Note: $\mathrm{PA}=$ price attentive, $\mathrm{QA}=$ quantity attentive, $\mathrm{PQA}=$ price and quantity attentive, $\mathrm{IA}=$ inattentive 
Figure 3. The effect of increasing the elasticity of marginal disutility with respect to labor, $\varphi$, from 0.1 to 0.15

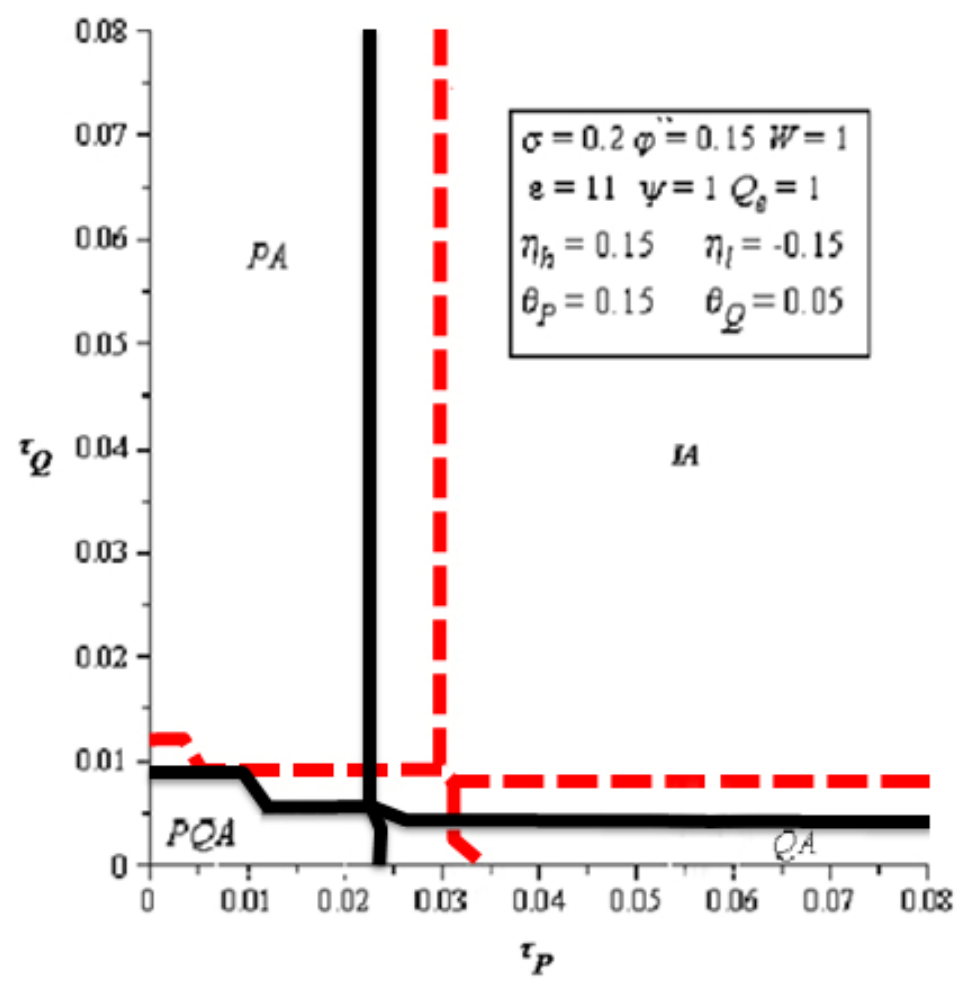

Figure 4. The effect of decreasing the nominal wage from $W=1$ to $W=0.9$

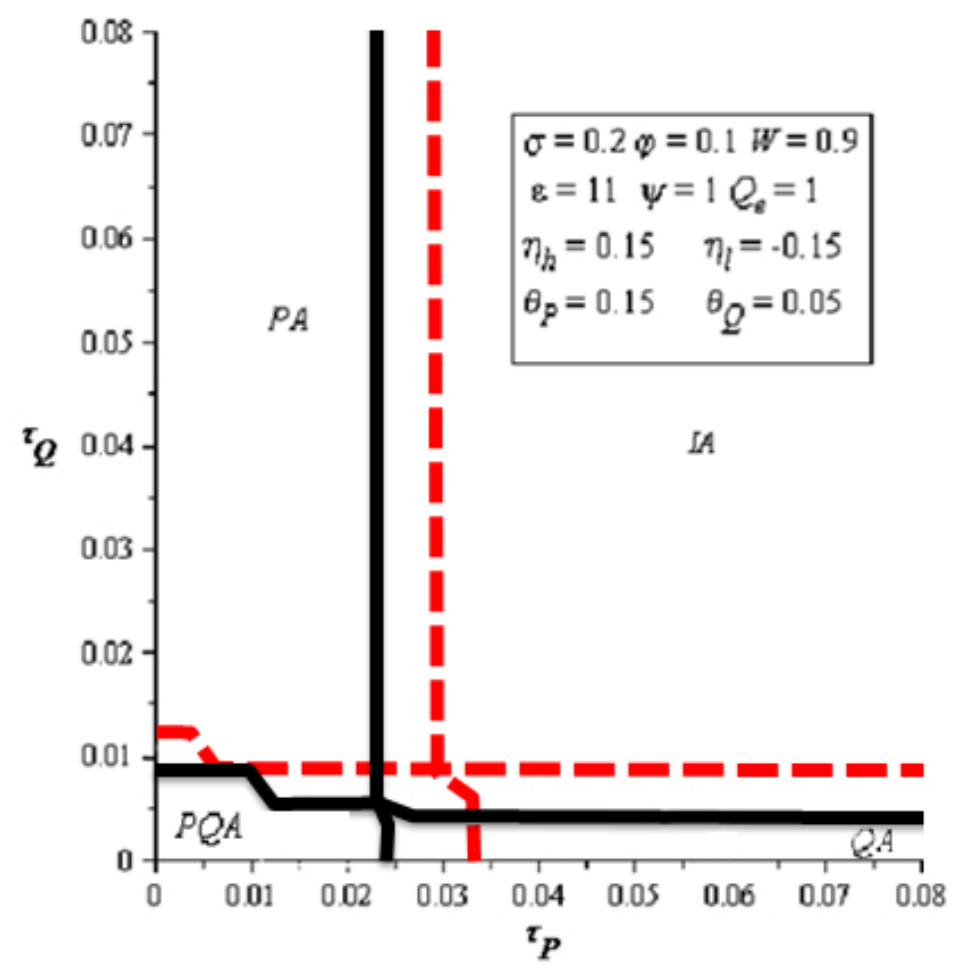

Note: $\mathrm{PA}=$ price attentive, $\mathrm{QA}=$ quantity attentive, $\mathrm{PQA}=$ price and quantity attentive, $\mathrm{IA}=$ inattentive 
Figure 5. The effect of increasing the fraction of the producers who experience cost shocks and adjust their goods' prices, $\theta_{P}$, from 0.15 to 0.2 .

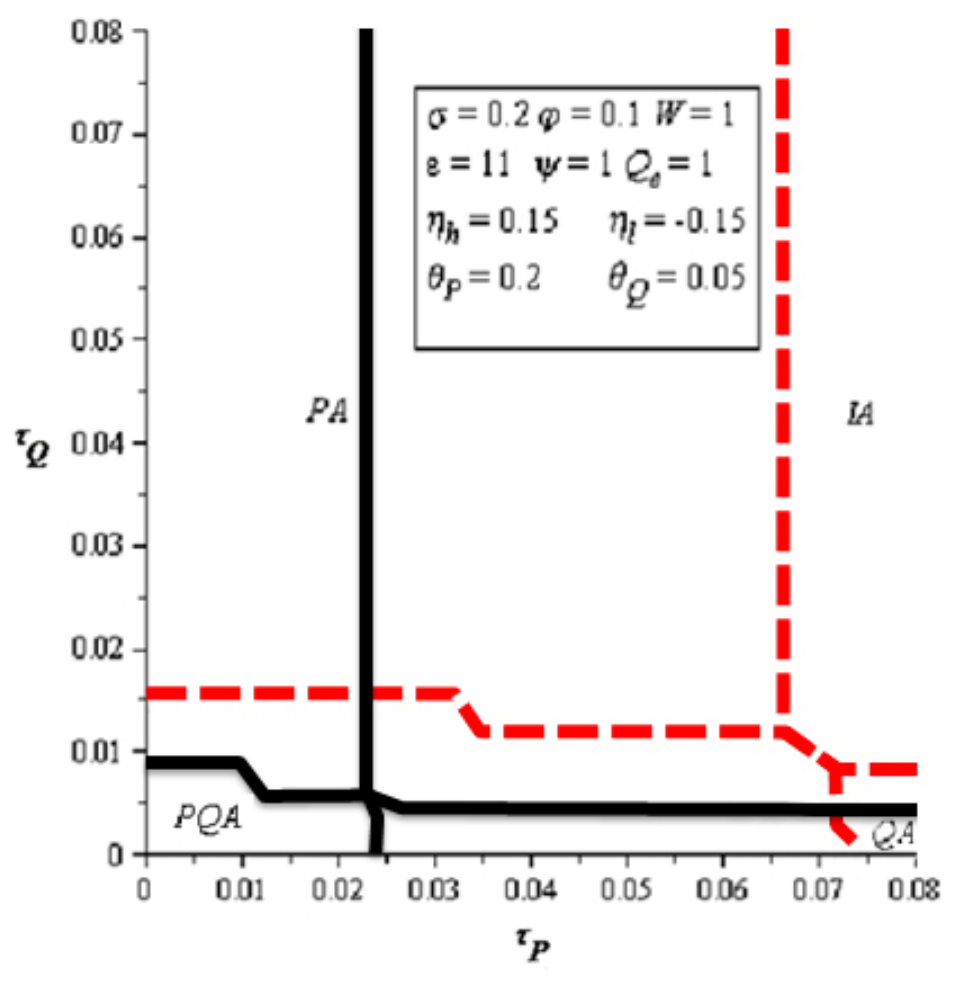

Figure 6. The effect of increasing the fraction of producers who experience marginal cost shocks and respond by adjusting goods quantity per package $\theta_{Q}$ from 0.05 to 0.1

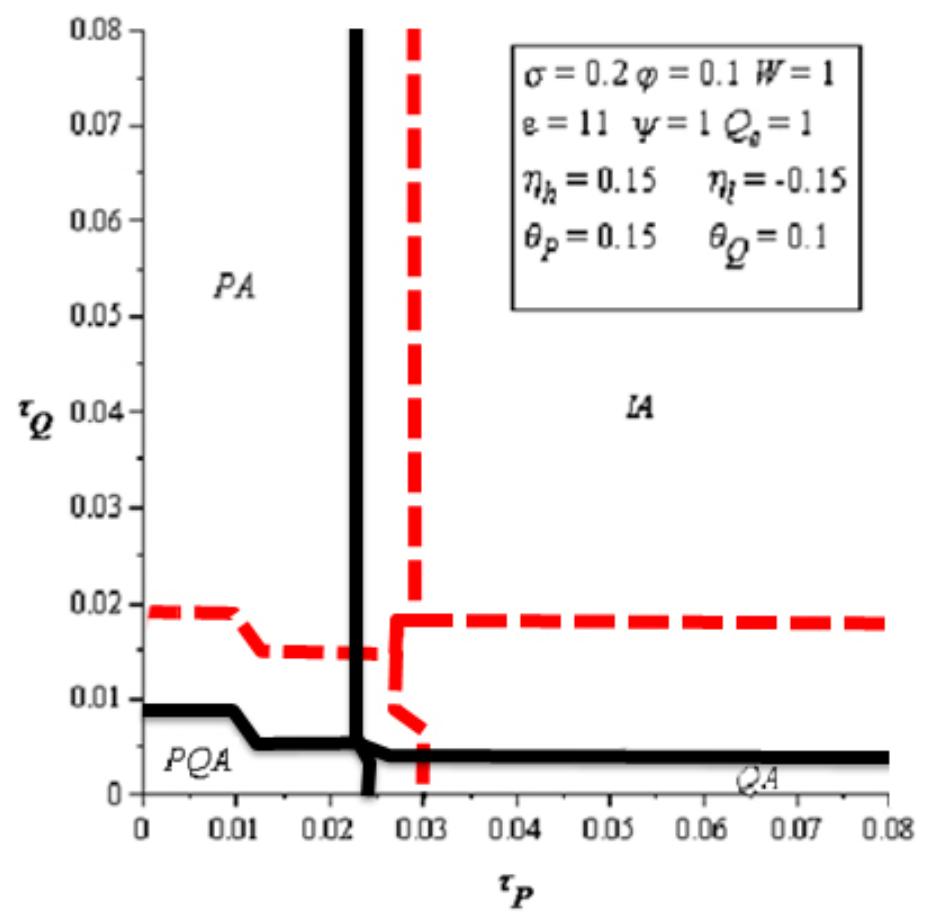

Note: $\mathrm{PA}=$ price attentive, $\mathrm{QA}=$ quantity attentive, $\mathrm{PQA}=$ price and quantity attentive, $\mathrm{IA}=$ inattentive 
Figure 7. The effect of increasing the elasticity of substitution, $\varepsilon$, from 11 to 21.

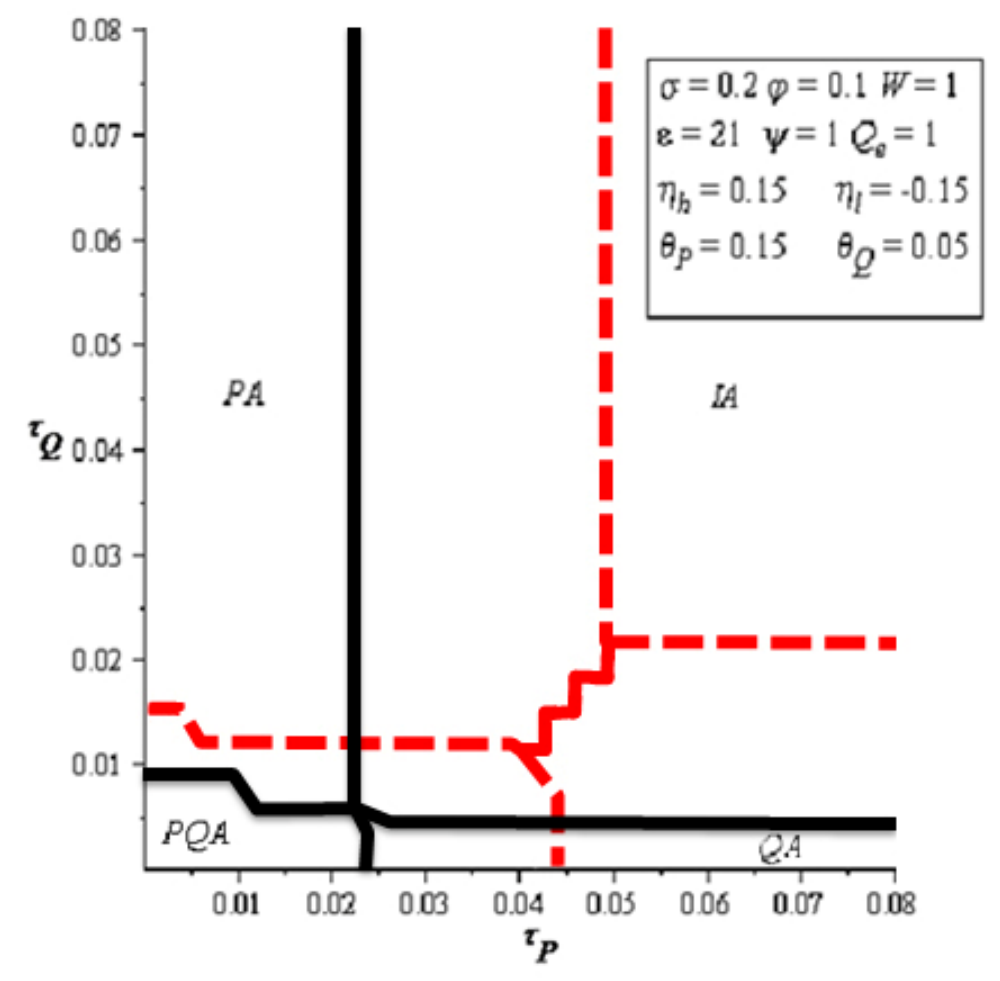

Figure 8. The effect of increasing the expected marginal cost, $\Psi$, from 1 to 3

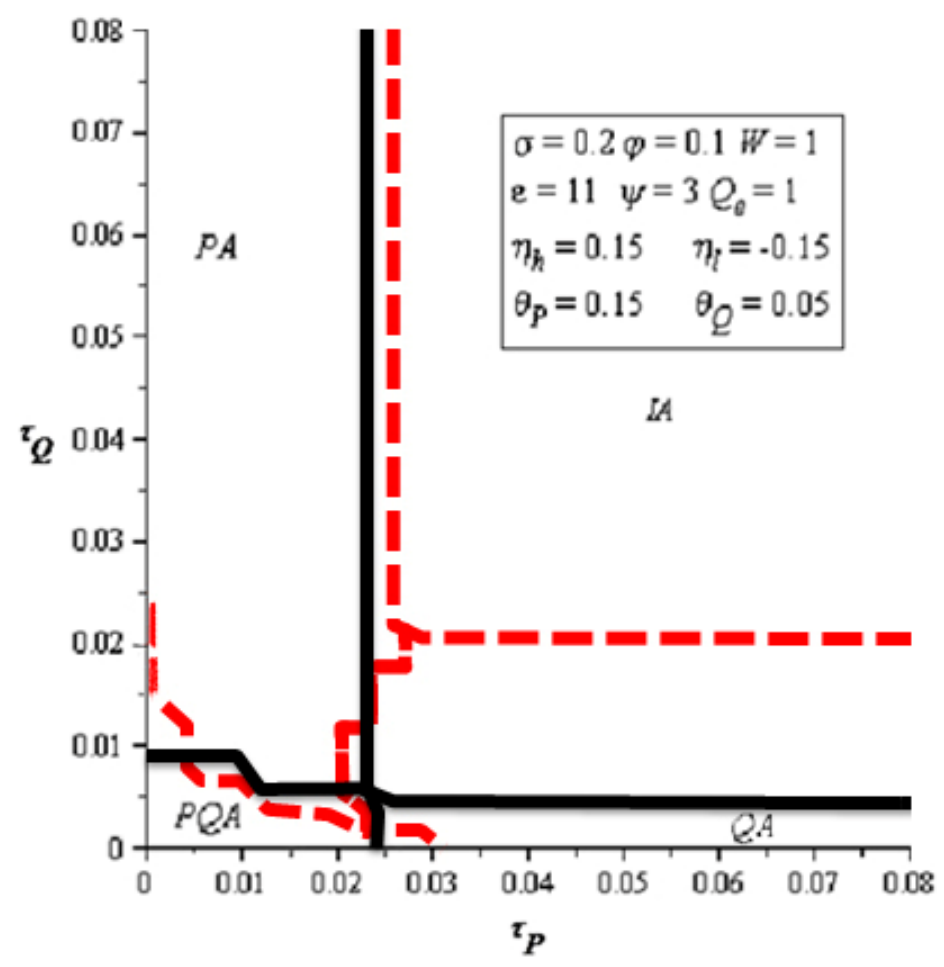

Note: $\mathrm{PA}=$ price attentive, $\mathrm{QA}=$ quantity attentive, $\mathrm{PQA}=$ price and quantity attentive, $\mathrm{IA}=$ inattentive 
Figure 9. The effect of increasing goods' expected quantity per package from 1 to 1.5

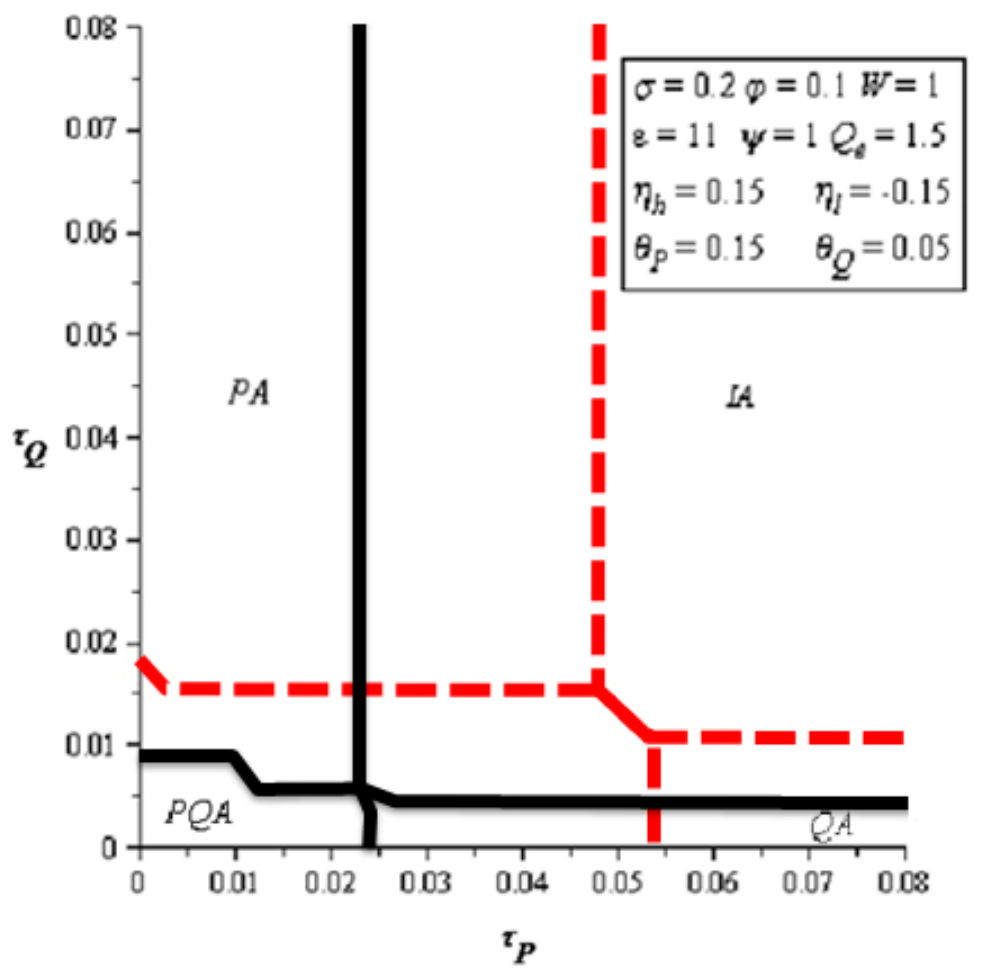

Figure 10. The effect of hanging the marginal cost shocks from $\eta_{l}=-0.15, \eta_{h}=0.15$ to $\eta_{l}=-0.2, \quad \eta_{h}=0.2$

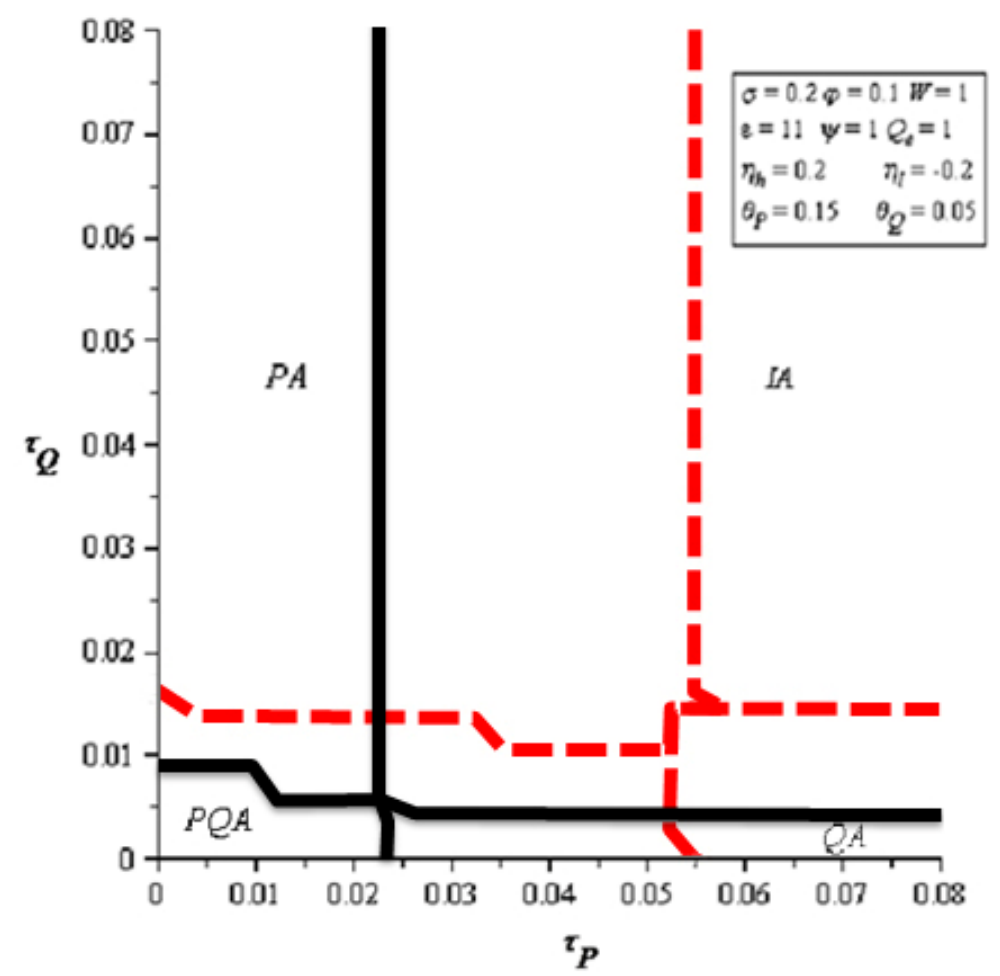

Note: $\mathrm{PA}=$ price attentive, $\mathrm{QA}=$ quantity attentive, $\mathrm{PQA}=$ price and quantity attentive, $\mathrm{IA}=$ inattentive 